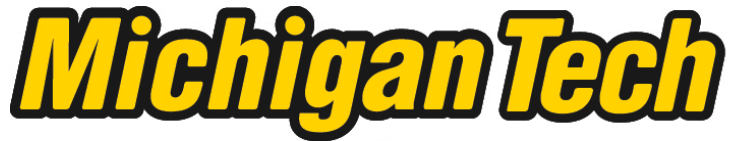 \\ Michigan Technological University Create the Future Digital Commons @ Michigan Tech
}

2015

HOUSEHOLD BIOSAND WATER FILTERS: MATERIALS, CAPACITY, AND TEMPERATURE EFFECTS ON PERFORMANCE

Nathan B. Arnold

Michigan Technological University

Follow this and additional works at: https://digitalcommons.mtu.edu/etds

Part of the Microbiology Commons, and the Water Resource Management Commons Copyright 2015 Nathan B. Arnold

\section{Recommended Citation}

Arnold, Nathan B., "HOUSEHOLD BIOSAND WATER FILTERS: MATERIALS, CAPACITY, AND TEMPERATURE EFFECTS ON PERFORMANCE", Master's Thesis, Michigan Technological University, 2015.

https://doi.org/10.37099/mtu.dc.etds/976

Follow this and additional works at: https://digitalcommons.mtu.edu/etds

Part of the Microbiology Commons, and the Water Resource Management Commons 


\title{
HOUSEHOLD BIOSAND WATER FILTERS: MATERIALS, CAPACITY, AND TEMPERATURE EFFECTS ON PERFORMANCE
}

\author{
By \\ Nathan B. Arnold \\ A THESIS \\ Submitted in partial fulfillment of the requirements for the degree of \\ MASTER OF SCIENCE \\ In Environmental Engineering \\ MICHIGAN TECHNOLOGICAL UNIVERSITY \\ 2015
}

(C) 2015 Nathan B. Arnold 
This thesis has been approved in partial fulfillment of the requirements for the Degree of MASTER OF SCIENCE in Environmental Engineering.

Department of Civil and Environmental Engineering

Thesis Advisor: $\quad$ Dr. Brain Barkdoll

Committee Member: Dr. Daisuke Minakata

Committee Member: $\quad$ Dr. Mark Rouleau

Department Chair: $\quad$ Dr. David Hand 


\section{Table of Contents}

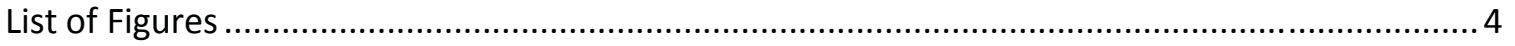

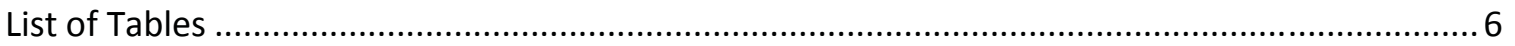

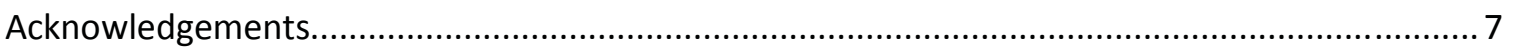

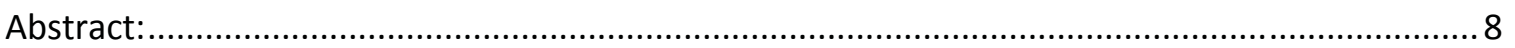

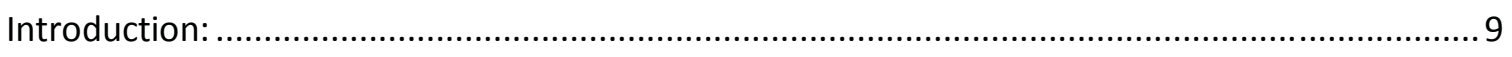

Chapter 1: The effect of using Ferrocement as a construction material....................................13

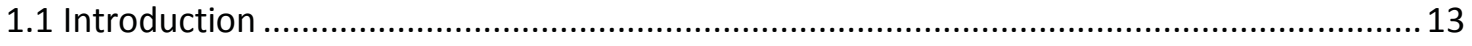

1.2 Materials and methods of the ferrocement investigation ............................................... 19

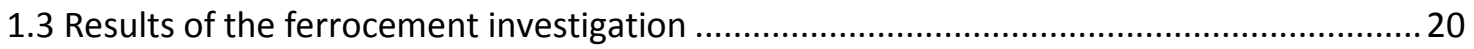

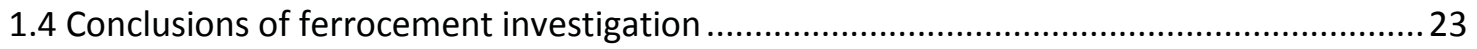

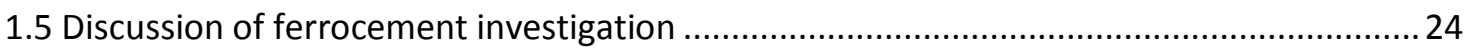

Chapter 2: Biosand filter enlarged body investigation ............................................................. 25

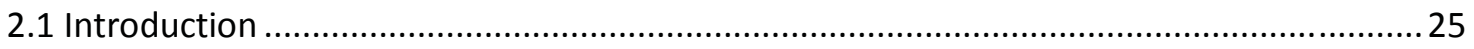

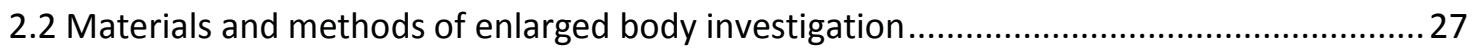

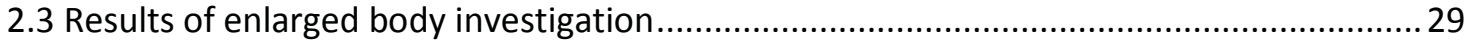

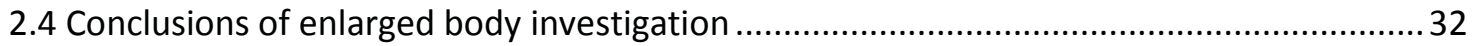

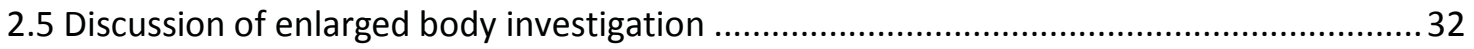

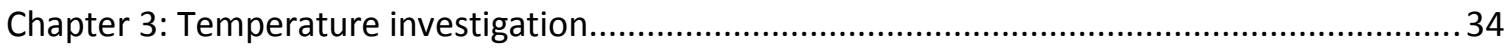

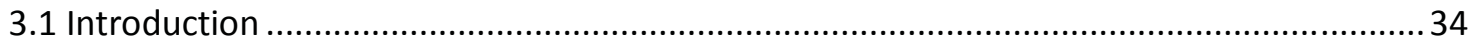

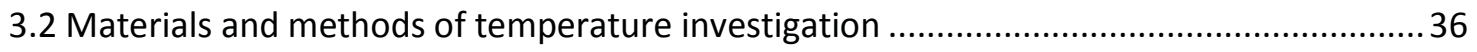

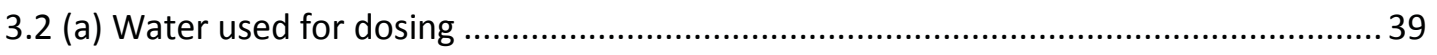

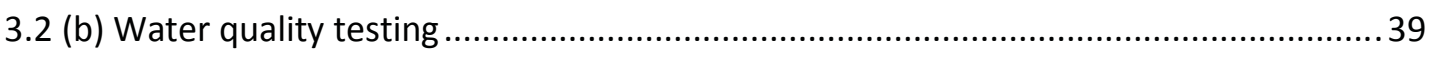

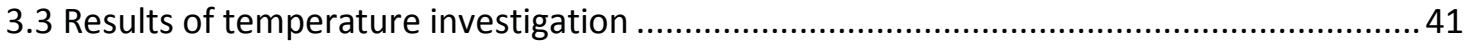

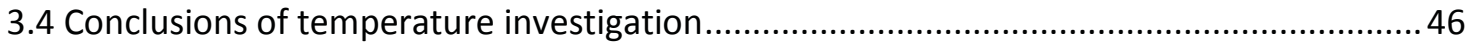

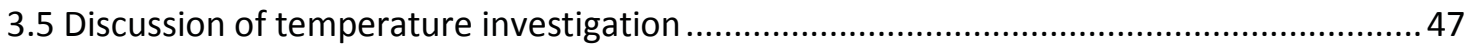

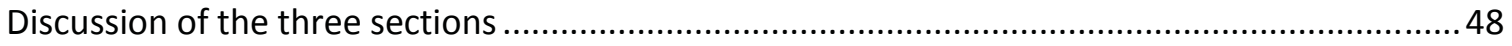

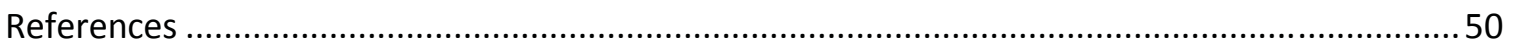

Appendix A - Ferrocement Biosand Filter Building Instructions ................................................5

Appendix B - Ferrocement Biosand Filter Performance Data.................................................... 61 


\section{List of Figures}

Figure 1. Schematic diagram showing the conventional dimensions of the BSF (drawing by author).

Figure 2. Schematic diagram showing the typical sand and gravel particle sizes and the order of layering (drawing by author).

Figure 3. Village of Cémaco in the Darién province of Panama where author worked in Peace Corps from 2012 to 2014 (photo taken by author).

Figure 4. Taimati River surrounding the village of Cémaco. A main source of village drinking water (photo taken by author).

Figure 5. Map of the country of Panama with the village of Cémaco marked by the yellow arrow pointing to the blue marker (Image from Google Earth Pro 2013).

Figure 6. Map of the village of Cémaco showing all homes, major landmarks, and portions of the Taimati River as well as its proximity to the community (Drawing by author).

Figure 7. 3M Petrifilms displaying the total coliforms (Red and blue dots) and E coli (blue dots) in $1 \mathrm{ml}$ of untreated drinking water (left) and filtered drinking water (right) following 24 hours of incubation. This sample was taken from the aqueduct in the town of La Cantera in rural Panama.

Figure 8. Graphs displaying the mean total coliform and E coli colony-forming units in unfiltered and filtered water. Error bars were calculated by dividing the standard deviation by the square root of the sample size ( 20 filters tested). Average reductions of $92 \%$ and $82 \%$ are shown for coliforms and E. coli respectively.

Figure 9. Schematic drawing of the enlarged FBSF used for this research. The body of this filter was expanded in diameter in order to yield a filter with greater capacity to store water between filtrations

Figure 10. Process of enlarged FBSF construction. The three photos from left to right show the filled cloth mold, the first layer of cement, and the finished shell before the addition of sand, gravel, and the outlet tube. This filter was used alongside a plastic V10 model filter for comparison.

Figure 11. Particle size distribution (PSD) graph of sand media added to the model BSFs. For use in defining the uniformity and other qualities of the soil used. PSD should be tested and controlled for sand to be used in BSFs.

Figure 12. Coliform removal as a function of dosage volume of the enlarged FBSF and the V10 BSF. The percent removal appears to decline at different rates for the two filters as the dose volume is increased on separate days of the experiment.

Figure 13. E.coli removal as a function of dosage volume of the enlarged FBSF and the V10 BSF. The percent removal appears to decline at different rates for the two filters as the dose volume is increased on separate days of the experiment. 
Figure 14. Schematic drawing of BSF model displaying dimensions. This model is vertically identical to the schematic given as Figure 1. Twelve identical filter models were constructed to these dimensions (drawing by author).

Figure 15. Schematic drawing of BSF displaying media sizes and order of layering. This model is vertically identical to the schematic given as Figure 2 . Twelve identical filter models were constructed to these dimensions (drawing by author).

Figure 16. Percent coliform removal of filters exposed to different ambient temperatures. The results of the first test following initial temperature changes are shown in orange alongside the results from the previous test (prior to treatment with different temperatures) in blue. Error bars calculated as +/- the standard deviation divided by the square root of the number of samples.

Figure 17. Percent E.coli removal of filters exposed to different ambient temperatures. The results of the first test following initial temperature changes are shown in orange alongside the results from the previous test (prior to treatment with different temperatures) in blue. Error bars calculated as +/- the standard deviation divided by the squar root of the number of samples.

Figure 18. Percent removal of coliforms and E.coli as a function of the time elapsed in the experiment. Blue lines encapsulate the window of time in which filters were held in separate temperature controlled labs (days 36 to 66 ). Before day 36 filters were all held at 18 degrees $C$. The final test on day 66 included only one filter in each controlled lab while eight of the filters were frozen.

Figure 19. Percent coliform removal over time during portion of experiment with filters in temperature controlled labs. This data is also shown in Figure 18 as the portion between the vertical blue lines.

Figure 20. Percent E.coli removal over time during portion of experiment with filters in temperature controlled labs. This data is also shown in Figure 18 as the portion between the vertical blue lines.

Figure 21. Coliform reduction in filters following freeze/thaw treatment at different temperatures. Error bars calculated as +/- the standard deviation divided by the square root of the number of samples.

Figure 22. E.coli reduction in filters following freeze/thaw treatment at different temperatures. Error bars calculated as +/- the standard deviation divided by the square root of the number of samples.

Figure 23. Instructions for FBSF construction in rural areas (visuals and instructions prepared by author). This is a multi-part figure and the descriptions of each step are given under each slide as parts $\mathrm{A}$ through $\mathrm{N}$. 


\section{List of Tables}

Table 1. The results of various BSF field studies measuring total coliform and $E$ coli removal. Percent reductions are calculated by subtracting the filtered colony counts from the unfiltered, dividing this value by the unfiltered count and multiplying by $100 \%$.

Table 2. Four examples of log base 10 reductions which are commonly used to describe the decreases in bacterial presence in water.

Table 3. The results of the enlarged filter body experiment including volume of influent, the test day, and percent removal of coliforms and E.coli. The V10 was a $17 \mathrm{~L}$ plastic filter. FBSF was a

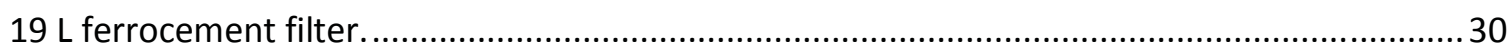

Table 4. Inferred characteristics of sand media added to the model BSFs. .................................38

Table 5. Results from the field testing of 20 ferrocement biosand filters in rural Panama. .........61 


\section{Acknowledgements}

The author would like to express gratitude to the following individuals for their contributions to this research: to the Wounaan people of Cémaco for their hospitality and friendship, to Peace Corps Panama for their project support and enthusiasm, to Dave Parrem and Emily Geiger for providing access to labs and resources, to Katie, Bob, and Casey Arnold for their ideas, edits, and AutoCAD expertize, to Ally Archer for her many hours of lab work and great company, to Candice Young-Rojanschi for her suggested research topics and guidance, to the CAWST organization for making their resources publically available, to Dr. Mark Rouleau for his great advice and statistical tutoring, to Dr. Daisuke Minakata for his edits and suggestions, and to Dr. Brian Barkdoll for the many hours he devoted to meetings and revisions as well as the incredible amount of support and resources he provided to make this research possible.

Thank you! 


\section{Abstract:}

The household biosand filter (BSF) is one of the world's most utilized point-of-use (POU) water treatment tools where drinking water is not reliably potable. The feasibility of using ferrocement for construction, the filter volume, and the effect of temperature on removal are unclear, however. The following field and laboratory research was carried out in Panama and at Michigan Technological University. Field testing of ferrocement biosand filters (FBSFs) in rural Panama yielded average coliform and E.coli removals that compared favorably to plastic and cement BSFs. Parallel testing of a larger-bodied FBSF and a conventionally-sized BSF revealed that the former is necessary to sufficiently purify dose volumes greater than the recommended 12 liter influent. Additionally, for optimal treatment, no more than approximately three-quarters of the total pore volume should be introduced per day. Model filters in different temperature labs showed that while immediate filter performance varies by temperature, over time, BSF performance adjusts to be similar for all tested temperature values. Finally, exposure to extremely reduced temperatures and freezing severely reduced filter performance compared to control filters. 


\section{Introduction:}

According to the World Health Organization roughly $88 \%$ of all cases of diarrhea are caused by unsafe drinking water, substandard sanitation, and improper hygiene (PrüssÜstün et al., 2008). There exist small and large scale tools to combat these threats, and for each tool research is necessary to legitimize its use. The ideal scenario to counter unsafe drinking water would be to deliver treated water to each individual household via pressurized pipes from a plentiful, protected source such as already exists in some nations. However, with that goal still potentially decades away for many communities with fewer economic resources, point-of-use (POU) water treatment tools are commonly used to improve the quality of water in the home (WHO, 2011). POU water treatment tools are used to improve water quality after delivery to the home and typically treat only the portion of the total flow designated for drinking (EPA, 2015). When used properly POU systems reduce the incidence of diarrhea by close to half (Lenton et al., 2005, Sobsey, 2008). Common POU treatments include solar disinfection, chemical treatment, and filtration.

The household biosand filter (BSF) has recently become one of the most popular POU filtration devices, with more than 500,000 units distributed between 1991 and 2015 (CAWST, 2015). The basic structure typically consists of a plastic or concrete shell, filled mainly with a sand media, with a discharge tube that is raised to a level such that a shallow layer of water is maintained over the top of the sand (Elliot et al., 2008) (Figures 1 and 2). When water is added to the filter, a pressure gradient is created which initiates flow out of the discharge tube. The flow rate decreases as the water level within the filter approaches the same level as the discharge tube. In a properly operating unit, a volume of filtered 
effluent equal to the dose volume should exit the filter before flow completely stops (Young-Rojanschi, 2014). During filtration pathogens are believed to be removed from water by the methods of trapping, natural die-off, adsorption, absorption and predation by other microscopic organisms (biological action). Those combined methods allow the filter to effectively deactivate a large percentage of pathogens significantly smaller in size than the openings between sand grains (CAWST, 2015). For example, given the 1 by $3 \mu \mathrm{m}$ size of $E$. coli cells, commonly used as filter performance indicators, and the vastly larger 760 $\mu \mathrm{m}$ diameter size of the sand grains used in the biosand filter, one does not expect to see removal by way of filtration even as smaller particles fill the filter gaps. Rather, the majority of removal of microscopic pathogens is attributed to the adsorption, absorption, and biological action within the filter (Reshes, 2007) (Cooke, 2000). During the first weeks of use BSFs have been observed to develop a schmutzdecke or filter cake in which a combination of particle buildup and biological growth develop in the uppermost inches of BSFs. This build up is thought to correspond to the peak pathogen removal efficiency of the BSF (Weber-Shirk, 1997). It is now believed that biological development occurs throughout the entire body of the BSF during its first weeks of use also contributing to greater pathogen removal (Elliot, 2011).

While the basic structures and functions of BSFs around the world are the same, differences in filter size, shape, and construction materials attempt to address local climate, use and cost conditions With the household BSF only in its second decade of existence, continued research is necessary to optimize its functionality in the field. Through experience in the Michigan Technological University (MTU) Peace Corps International 
(PCMI) Program in Panama and in Michigan the author was able to observe and test a variety of different BSF's both in the field and in laboratory settings.

The three topics investigated in this research are as follows: 1) the effectiveness of ferrocement biosand filters (FBSFs) as compared to previously proven construction materials for E. coli and total coliform removal, 2) a comparison of the removal of E. coli and total coliforms in a FBSF with an enlarged body and water storage capacity to a BSF of standard dimensions, and 3) an investigation of the effect of temperature on the ability of BSFs to remove E. coli and total coliforms. The first two topics were investigated using full scale BSFs, while the third used lab-scale models. Practical instructions for construction of a FBSF are included as part of Topic 1. The goals of conducting research on these three topics are to advance the available knowledge of the construction, sizing, and installation of BSF in the field.

The three sections included in this thesis are related to one another in that the insights gleaned from one experiment affect the design of the remaining two, and that the cumulative results increase the understanding of factors affecting the implementation of BSFs in the field. For example, the knowledge that the FBSF performs relatively well in the field is necessary before the design and testing of a FBSF with an enlarged body. Similarly, knowledge regarding the effect of ambient temperature on filter performance is useful in the design of the enlarged body experiment where rapid microbial development (ripening) is desired. 


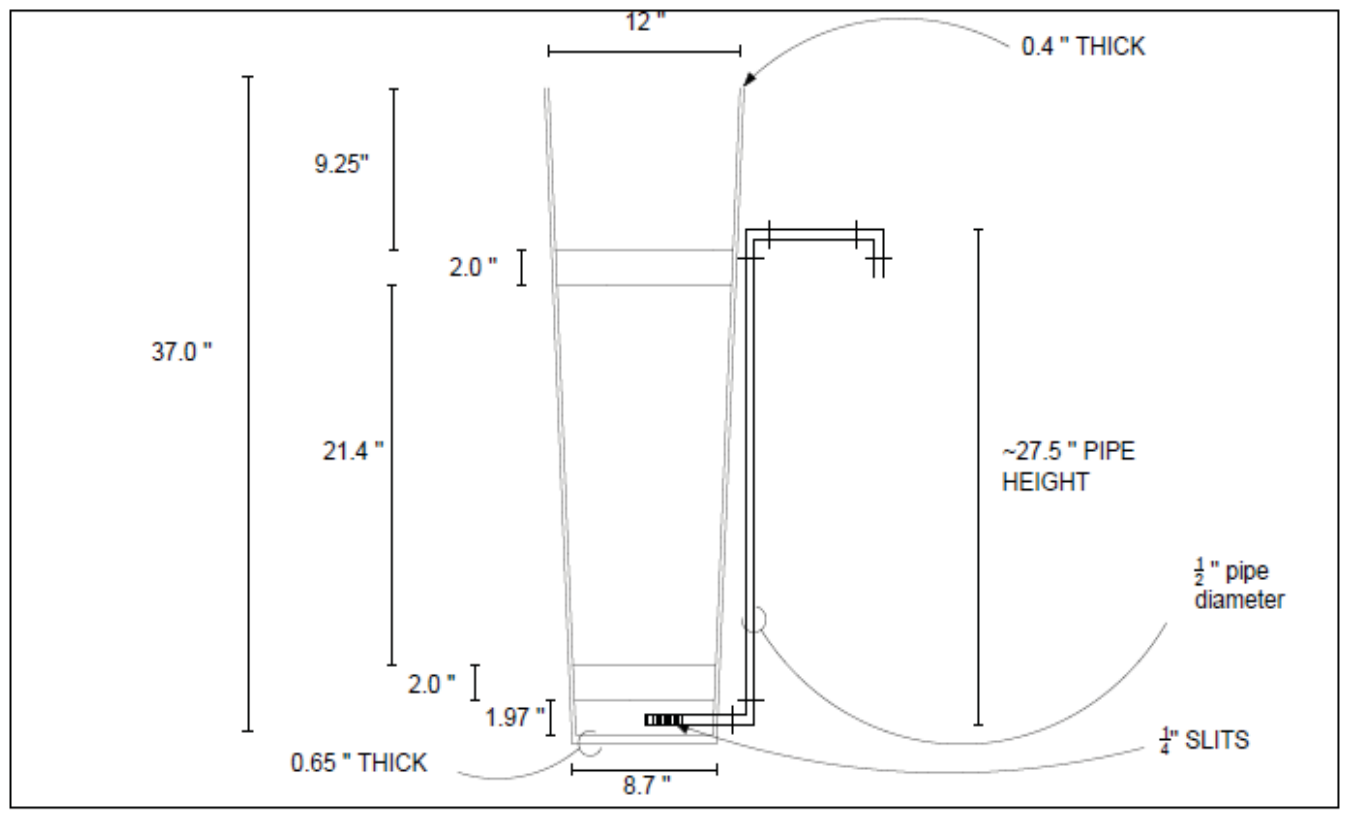

Figure 1. Schematic diagram showing the conventional dimensions of the BSF (drawing by author). 


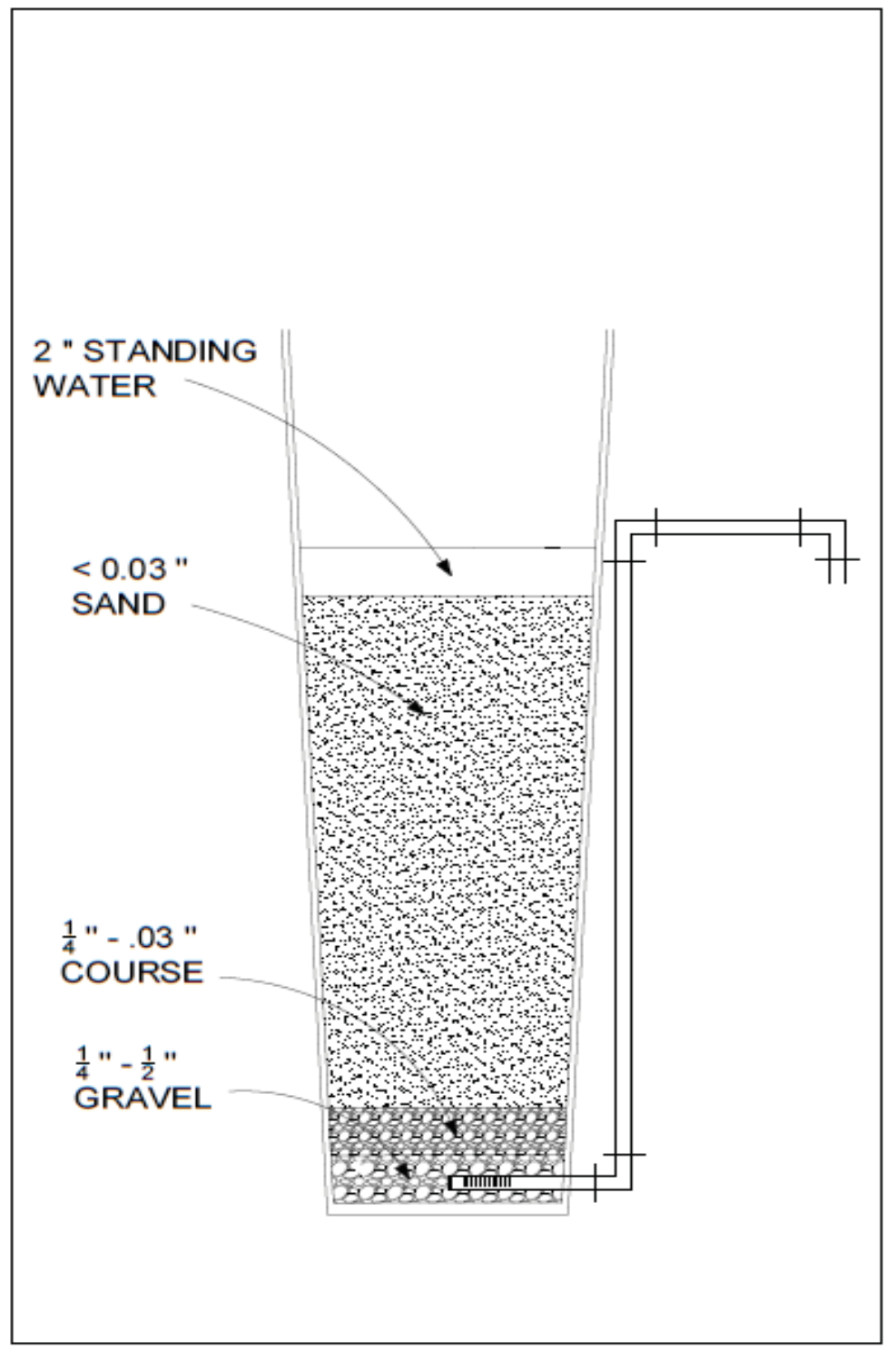

Figure 2. Schematic diagram showing the typical sand and gravel particle sizes and the order of layering (drawing by author).

\section{Chapter 1: The effect of using Ferrocement as a construction material}

\subsection{Introduction}

The objective of this investigation was to assess whether ferrocement is a viable material for BSF shell construction. This was accomplished by comparing the field 
performance of filters constructed from ferrocement to those assembled with conventional materials.

Ferrocement is a versatile material used commonly for the construction of tanks, slabs, boats, and roofing. It is generally defined as a combination of mortar with wire-mesh reinforcement which results in a thin-walled, flexible, and durable material (Suleiman, 2013). One difference between ferrocement and reinforced concrete is that the specific surface area of reinforcement is much higher in ferrocement which is thought to increase the tensile strength of the material (Shah, 1991). While concrete BSFs are common around the world, the use of ferrocement or even reinforcement for cement BSF construction has not been researched or field tested.

Within the Panama branch of the Peace Corps ferrocement is most commonly used for the construction of water tanks, ranging from 200 to 4000 liters, which can be connected to new or existing aqueducts in order to improve water availability in rural communities. Volunteers and community members have found ferrocement to be an appropriate tool because of its versatility, strength, and low cost (Shaw, 1981). It is also a good option in remote areas with little access to more advanced, less ubiquitous building materials needed for steel frameworks and molds. The materials for constructing FBSFs are readily available in almost every community in Panama in the way of sand, gravel, wire, cement, and tubing. In 2013, the Peace Corps began partnering with the residents of a small indigenous Pacific Coast community called Cémaco, in the Darién province of Panama, to build shells for BSFs using ferrocement and other locally-available materials. Cémaco was an ideal site for this endeavor since the town's drinking water was untreated river water to 
which there is currently no road access. Also, the residents desired cleaner water but lacked the economic means to purchase basic water treatment tools, and the area has a large amount of the natural building materials, such as sand and gravel, necessary for BSF and ferrocement construction (Figs. 3, 4, 5 and 6). Following the construction of six FBSFs in Cémaco, a second project was initiated in La Cantera, a similarly small, rural town in the Darien Province of Panama, in which 30 more FBSFs were constructed.

In past studies slight differences in microbial removal have been observed between filters constructed from different materials. It has been postulated that this difference is due to leaching of matter from the filters' walls, such as lime from concrete which affects the $\mathrm{pH}$ of water, or from the different textures of the materials, allowing water to flow downward more or less tortuously along the walls (Gimbel, 2006).

Given the variability of inter-filter performance with different shell materials it is necessary to test the viability of a filter constructed from any new material. While concrete and ferrocement are very similar in their use of cement and aggregate, they differ in that ferrocement construction incorporates metallic wire mesh reinforcement. Also, the use of a steel mold, necessary in the construction of concrete BSFs, is absent during ferrocement construction. This difference gives the FBSF, built by plastering the concrete onto wire mesh, a rougher wall texture which could affect the downward flow of water.

Three months after the construction of FBSFs in Cémaco and La Cantera, 20 of the BSFs were tested for total coliform and E. coli removal with the objective of establishing the FBSF's performance in the field. 


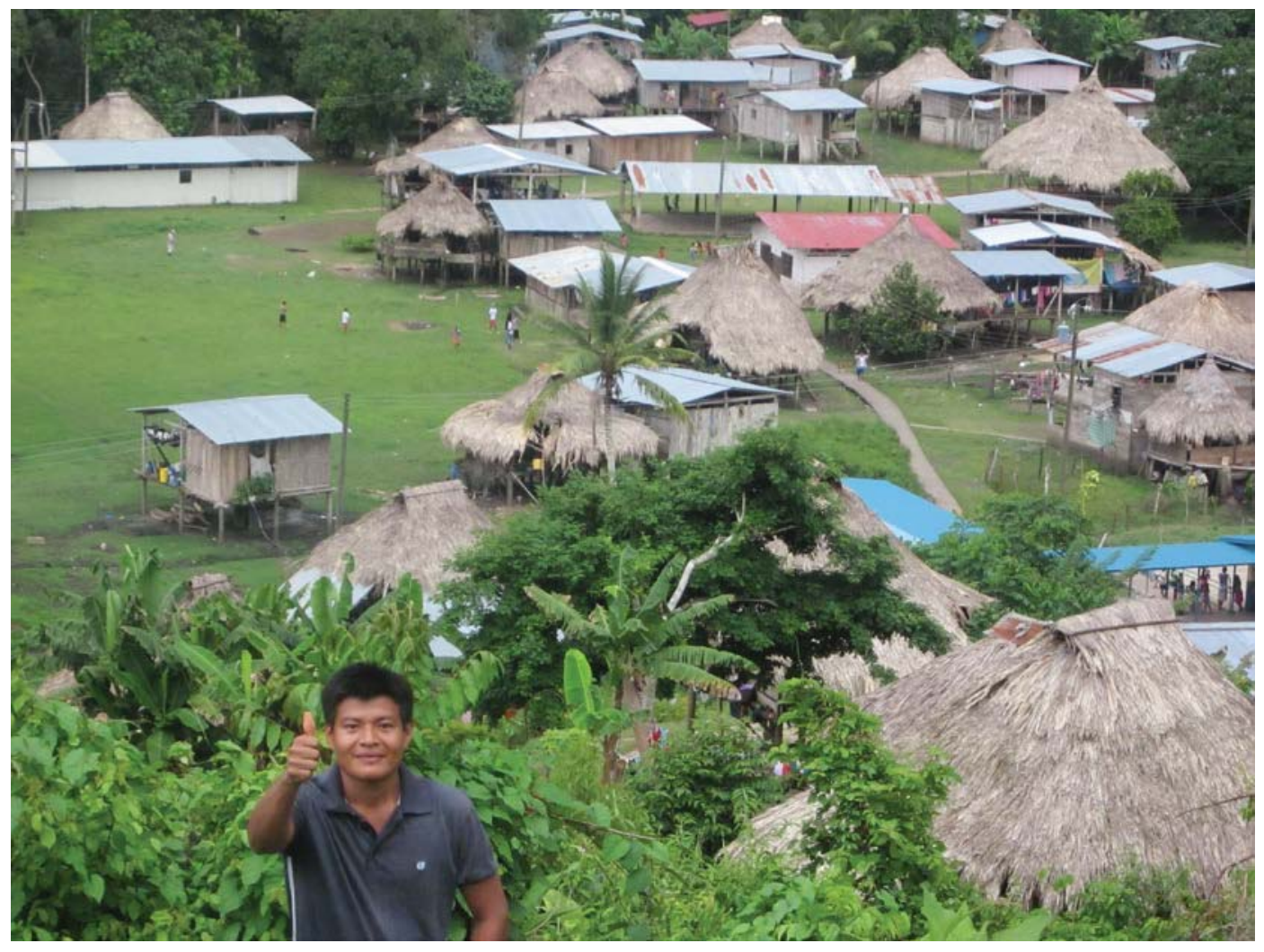

Figure 3. Village of Cémaco in the Darién province of Panama where author worked in Peace Corps from 2012 to 2014 (photo taken by author). 


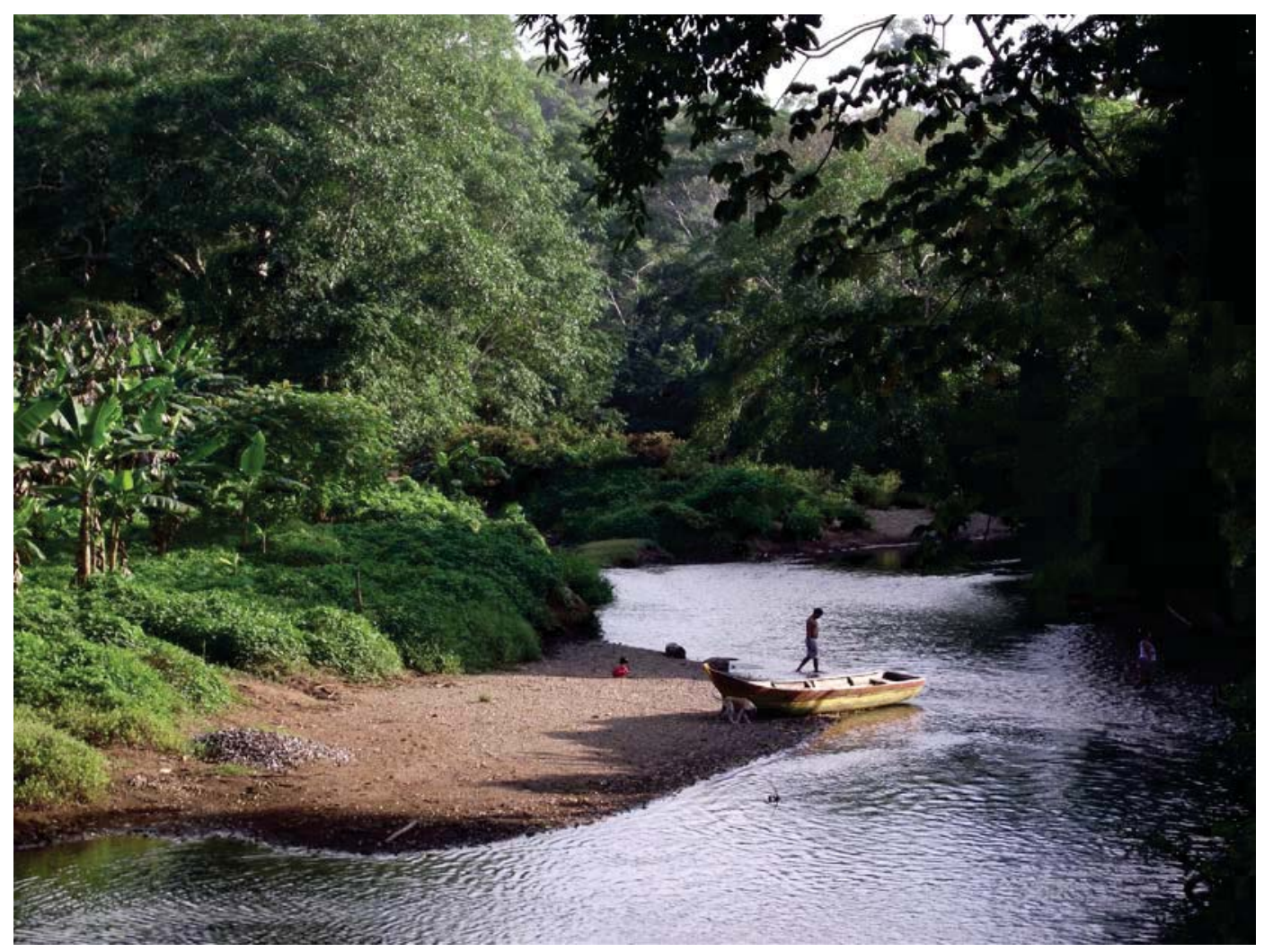

Figure 4. Taimati River surrounding the village of Cémaco. A main source of village drinking water (photo taken by author).

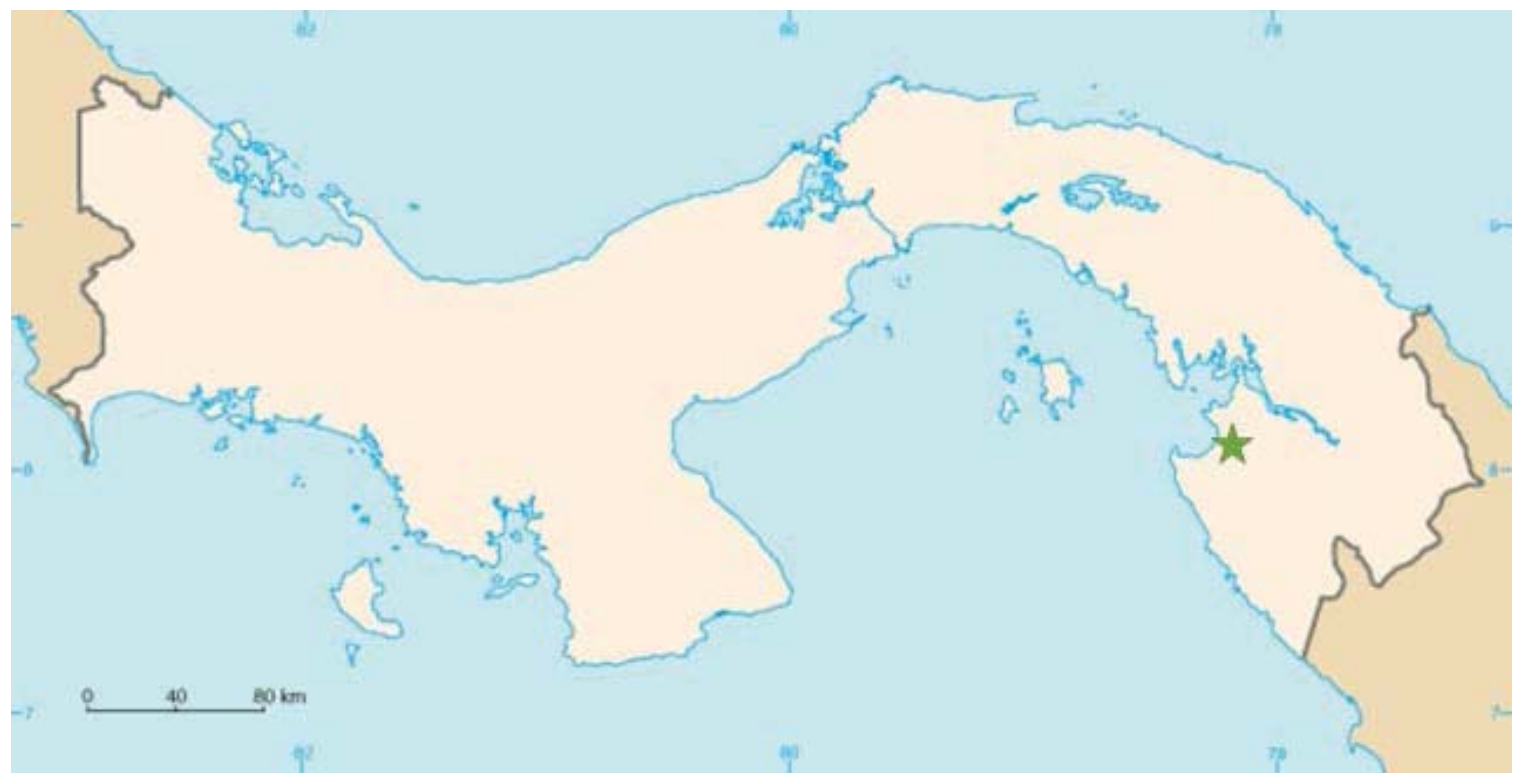

Figure 5. Map of the country of Panama with the location of the village of Cémaco marked by the green star. (This is a public domain image taken from Wikimedia commons https://commons.wikimedia.org/wiki/File:Panama-mapblank.png). 


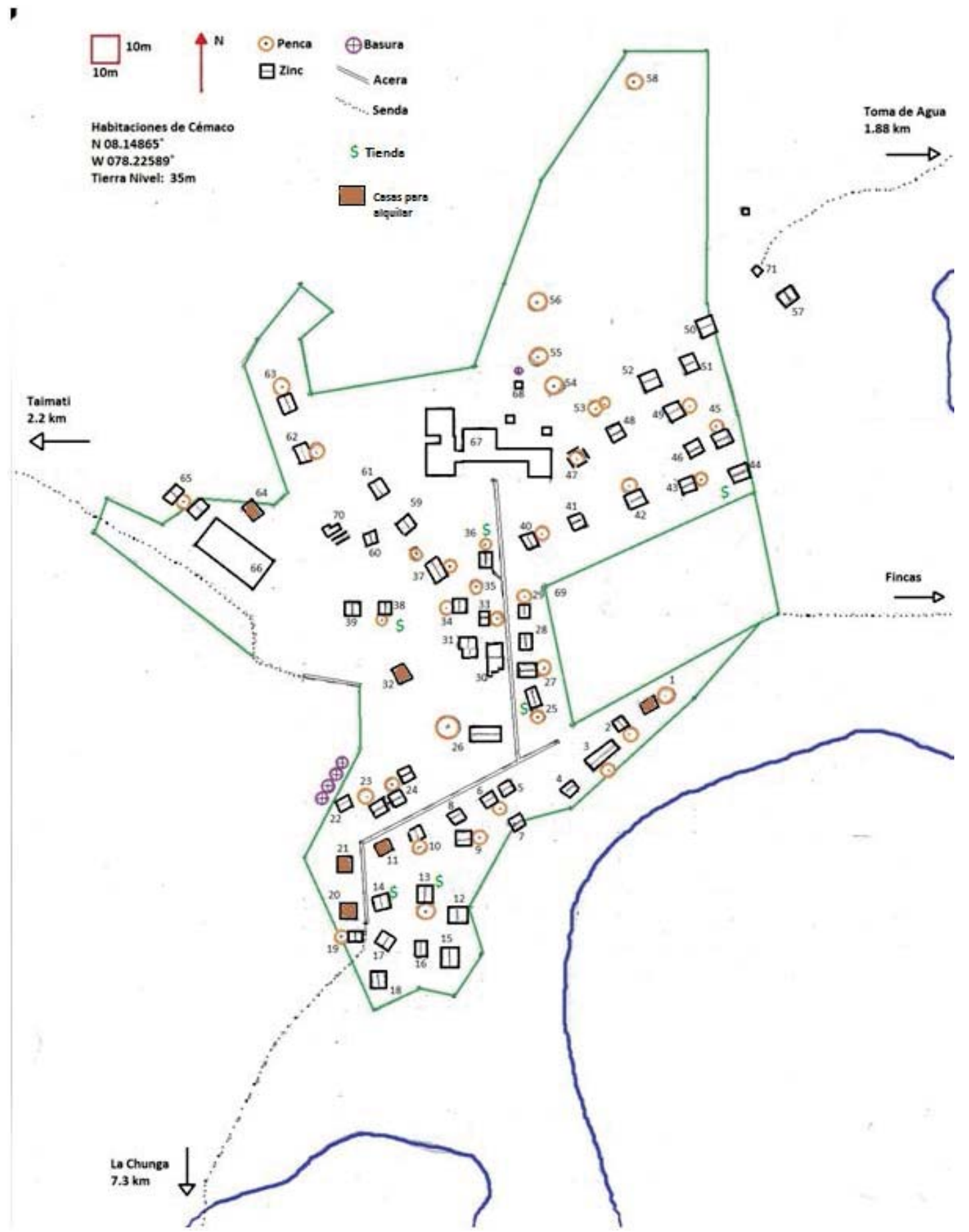

Figure 6. Map of the village of Cémaco showing all homes, major landmarks, and portions of the Taimati River as well as its proximity to the community (Drawing by author). 


\subsection{Materials and methods of the ferrocement investigation}

A set of instructions for the construction of FBSFs was prepared in English and Spanish and is available in English as slides in the appendix. The cement and 18 gauge hex netting wire ("chicken wire") used for construction in Cémaco was brought in by boat and horseback. The sand and gravel were collected from an area on the edge of the river, sieved, and then washed. Three differently sized sieves were used to separate the sand and gravel into three sizes corresponding to the grain size ranges shown in Figure 2. Filter construction closely followed the instructional slides given in the appendix. The sand and gravel were used to fill the filters to the heights shown in Figures 1 and 2. All filters were in use for at least three months before samples were taken.

Prior to sampling from each BSF, owners were asked to collect water from their most commonly frequented water source using their own water storage device (WSD). Sources ranged from the nearest river to the household tap, and WSDs were typically 20 liter (5 gallon) buckets. The water was stirred and a one milliliter sample was plated on a $3 \mathrm{M}$ Petrifilm using a Pipetman with a sterile, disposable tip in accordance with 3M instructions $\left(3 \mathrm{M}^{\mathrm{TM}}, 2015\right)$. The remainder of the water was then poured directly into the filter inlet initiating flow out of the discharge tube. The first five milliliters of this effluent were captured using sterile whirlpacks from which another one ml sample was taken and plated. In the absence of electricity nearby, the samples were placed together between two stiff pieces of cardboard and strapped to the sampler's body for 24 hours of incubation after which the colonies could be visually counted and recorded (Figure 7). 


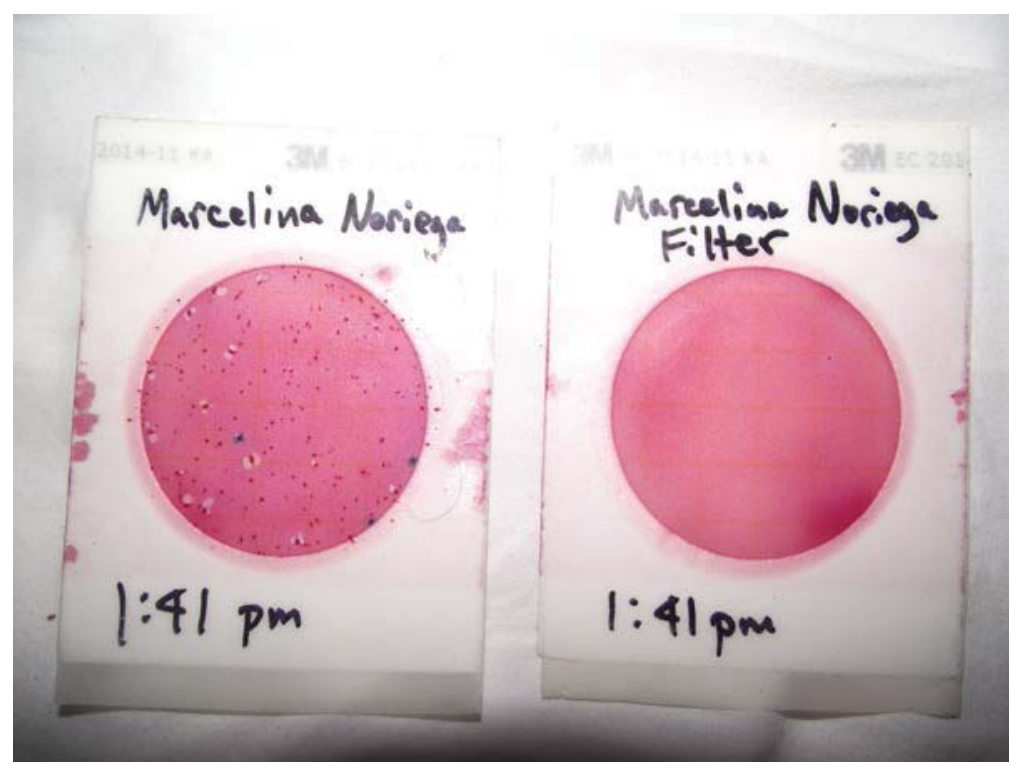

Figure 7. $3 \mathrm{M}$ Petrifilms displaying the total coliforms (Red and blue dots) and E coli (blue dots) in $1 \mathrm{ml}$ of untreated drinking water (left) and filtered drinking water (right) following 24 hours of incubation. This sample was taken from the aqueduct in the town of La Cantera in rural Panama.

\subsection{Results of the ferrocement investigation}

Results from the coliform and E. coli tests of 22 of the original 36 filters constructed in Panama are shown as a graph in Figure 8. The raw data contributing to this figure is given in Table 4 of the appendix. In 18 of the 20 , or $90 \%$ of homes surveyed, fewer total coliforms were observed in filtered water compared to unfiltered water. Unfiltered water in 15 of the 20 homes contained countable E. coli colony forming units (CFUs). In 13 of those 15 homes, or $87 \%$, a reduction in E. coli CFUs was observed in filtered water. One home which began with no E. coli in their unfiltered water sample, showed a single CFU in their filtered water. A paired T-test using SPSS statistics software showed that there was a significant reduction in both total coliform and E. coli colony forming units (CFU) in filtered versus unfiltered water with P-values of less than 0.001 in both cases. The mean countable coliform and E. coli CFUs before filtering were 179.61 and 2.14 with standard error values of 20.4 and 0.52 , respectively. Following filtration the mean countable CFUs 
were reduced to 13.7 and 0.38 with standard error values of 4.27 and 0.20 , respectively. The reductions are equivalent to a $92 \%$ reduction of the mean total coliform CFUs and an $82 \%$ reduction of the mean E. coli CFUs.

A literature review of past field studies where coliform and E. coli removal efficiencies were tested in filters constructed with conventional materials (nonferrocement) revealed average removals of 66.3 and 79.9\% respectively (Table 1) (Stauber, 2006; Stauber, 2009; Duke, 2006; Fiore, 2010; Tiwari, 2009). The results shown in this table can be converted into log reductions according to Table 2. While one study of concrete filters in Haiti showed an average reduction of E. coli that approached 2-log, the majority of field tests observed single log reductions or less.

Table 1. The results of various BSF field studies measuring total coliform and E coli removal. Percent reductions are calculated by subtracting the filtered colony counts from the unfiltered, dividing this value by the unfiltered count and multiplying by $100 \%$.

\begin{tabular}{|c|c|c|c|c|}
\hline Reference & $\begin{array}{l}\text { Total coliform } \\
\text { reduction }(\%)\end{array}$ & $\begin{array}{l}\text { Ave E. coli } \\
\text { reduction ( } \%)\end{array}$ & Location & $\begin{array}{l}\text { Filter } \\
\text { material }\end{array}$ \\
\hline $\begin{array}{l}\text { C.E. Stauber } \\
(2006)\end{array}$ & -- & 93 & $\begin{array}{l}\text { Dominican } \\
\text { Republic }\end{array}$ & Plastic \\
\hline $\begin{array}{l}\text { C.E. Stauber } \\
(2009)\end{array}$ & -- & 48 & $\begin{array}{l}\text { Dominican } \\
\text { Republic }\end{array}$ & Concrete \\
\hline $\begin{array}{l}\text { W.F. } \\
(2006)\end{array}$ & -- & 98.5 & Haiti & Concrete \\
\hline $\begin{array}{ll}\text { Fiore } & \text { M.M. } \\
(2010) & \end{array}$ & -- & $\begin{array}{l}80 \quad \text { (median } \\
\text { value) }\end{array}$ & Nicaragua & Not given \\
\hline $\begin{array}{l}\text { Tiwari S.S.K. } \\
(2009)\end{array}$ & 66.3 & -- & Kenya & Concrete \\
\hline
\end{tabular}


Table 2. Four examples of log base 10 reductions which are commonly used to describe the decreases in bacterial presence in water.

\section{Log reduction}

Corresponding percent reduction

\begin{tabular}{ll}
\hline $1-\log$ & $90 \%$ \\
$2-\log$ & $99 \%$ \\
3-log & $99.9 \%$ \\
$4-\log$ & $99.99 \%$ \\
\hline
\end{tabular}



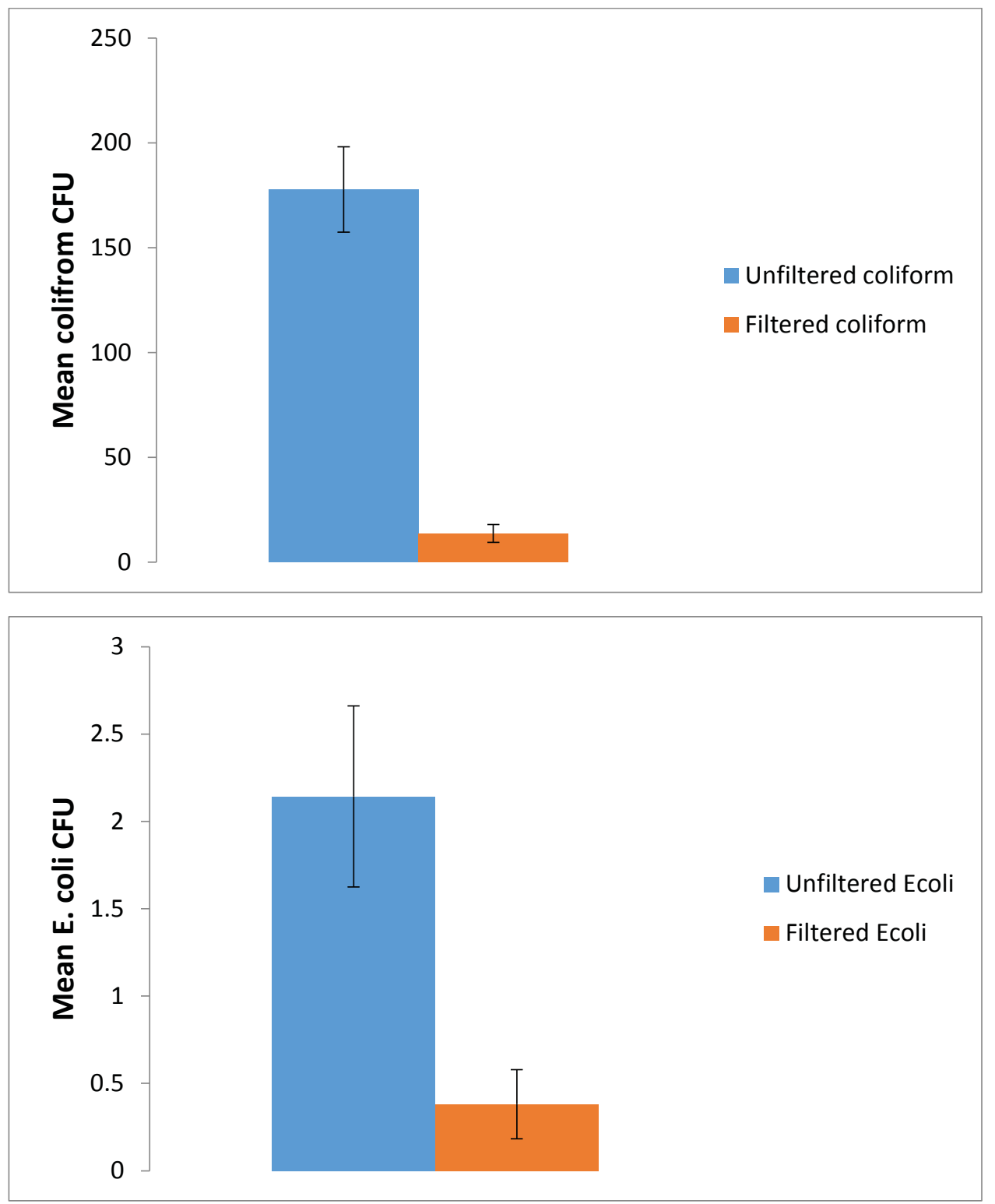

Figure 8. Graphs displaying the mean total coliform and E coli colony-forming units in unfiltered and filtered water. Error bars were calculated by dividing the standard deviation by the square root of the sample size (20 filters tested). Average reductions of $92 \%$ and $82 \%$ are shown for coliforms and E. coli respectively.

\subsection{Conclusions of ferrocement investigation}

The objective of this chapter was met, therefore, in that the use of ferrocement is shown here to be a viable material for BSF construction since reduction of both total 
coliforms and E. coli in filtered versus unfiltered water was shown to be both statistically significant and on par with test results of BSFs of different materials as shown in Table 1.

The overall reduction of the average coliform and E. coli counts supports the viability of the FBSF in the field as a tool for improving the quality of water. These findings add to the existing knowledge regarding potential BSF shell materials which has in the past received relatively little attention in field and laboratory tests.

\subsection{Discussion of ferrocement investigation}

While field tests of existing POU filters tend to achieve significant reductions of water contaminants, they rarely reach World Health Organization (WHO) standards for safe, consumable water which sets the goal of total exclusion of coliforms and E.coli (WHO, 2011). In order to achieve water purity that meets these standards, the use of FBSFs should be seen as a first step, removing the majority of turbidity and live pathogens, so that chlorination or other secondary treatment becomes more effective (WHO, 2015). As a side note, in the few coliform/E.coli tests run on Cémaco water samples treated with filtration and followed by chlorination (not shown in this paper), no live pathogens were detected.

More data on coliform/E.coli removal in FBSFs since sampling from 20 filters was not sufficient for the data to be normally distributed as is necessary for more thorough statistical comparisons. Research is also needed on the removal rates of other pathogens, both organic and inorganic, in order to justify wider use of the FBSF.

The advantages of building BSF shells with ferrocement are that they are inexpensive (around \$7 per shell in Panama), the materials are readily available in most communities, and the shape of the filter can be varied which will be further touched on in 
the next chapter. The main objections to the process are that it is time consuming and that the shells can crack if allowed to dry out, requiring more layers of cement to repair.

\section{Chapter 2: Biosand filter enlarged body investigation}

\subsection{Introduction}

The objective of this research was to investigate an optimal sizing method for BSFs given differing water requirements among users. The research compares the performances of two different size filters receiving varying volumes of influent. The results are used to help design a method for tailoring BSF body sizes to have the highest possible removal efficiencies while not wasting space or materials.

Water within BSFs moves similarly to a plug flow so that when a new dose is added to the inlet the first water to leave the exit pipe is water that has been stored within the filter from the previous dose (Elliot, 2008). The BSF is used intermittently (when users add water) and the time between doses is referred to as the idle period. During the idle period a volume of water referred to as the pore space volume, equal to the total volume of the pore space between the sand grains is stored within the filter. Recent studies have shown that greater pathogen removal occurs if the following two criteria are met: 1) the idle period is extended, ideally reaching 24 hours and 2) the filter's pore volume within the filter is at least as great as, ideally greater than, the dose volume introduced. Both these criteria have the effect of allowing water to sit within the filter before it becomes effluent which the user will drink. While the exact mechanism for pathogen removal is unknown, experiments suggest that organisms within the filter graze upon the live pathogens throughout the idle 
period (Elliot 2011). This theory of operation also means that one should not add influent that is greater in volume than the pore space of the filter body otherwise the filtered effluent will include some water which has not benefited from an idle period.

In 2012 the Version 10 (V10) BSF was introduced which raised the levels of the sand and the outlet tube, effectively reducing the possible dose volume and increasing the filter pore volume (CAWST, 2015). Ideally, in the V10 BSF no water passes through the filter without the benefit of a 24 hour idle period. The raised sand and outlet tube, however, have the potentially negative effect of reducing the space above the sand and thus the amount of water the user can add in a single batch to about 12 liters. Reasonably, users requiring more than 12 Liters per day might add a second batch of untreated water in order to meet their water consumption needs, exceeding the filter's pore space so that some of the effluent would not benefit from an idle period. One possible solution would be to increase the volume of the body of the filter without reducing the space available for dosing above the sand. This would take the form of a larger bodied filter which would store more water between uses. While the enlarged filter body could take an infinite number of shapes, one option developed for this research is presented in Figure 9.

Using ferrocement, a FBSF was constructed with the enlarged dimensions given in Figure 9. For the purpose of comparing the pathogen removing abilities of the large-bodied FBSF to the V10 model BSF, a water/sewage mixture was run through each for 30 days and the percent removals of coliforms and E. coli were measured. 
2.2 Materials and methods of enlarged body investigation

This study began with the construction of a FBSF with enlarged dimensions matching those given in Figure 9. The construction process followed the instructions previously described in Chapter 1 and given in the Appendix, except that the cloth mold, over which cement was plastered, was tailored to produce an enlarged bodied filter (Figures 9 and 10). A plastic BSF was also purchased from Triple Quest, the dimensions of which match the V10 BSF shown in Figure 1 (Triple Quest, 2015).

The fill media was a sand and gravel purchased from Red Flint Sand and Gravel which obtains its media from glacial deposits in Eau Claire, Wisconsin (Red Flint, 2015). The media was washed and analyzed using varying-sized sieves. The bottom drainage gravel ranged in size from 12.5 to $6.35 \mathrm{~mm}$ in diameter and the smaller gravel directly beneath the sand was between 6.35 to $0.8 \mathrm{~mm}$. The filters were slowly filled from the bottom so that the pore space volume (volume of water needed to fill each filter) could be measured. The respective pore space volumes of the V10 filter and the FBSF were found to be approximately 14 and 19 liters. The pore volume of the FBSF could be increased to approximately 24 liters if the entire filter body were filled with media, however, for the purpose of this experiment filter media in the FBSF was filled only to the same height as in the V10 BSF. The FBSF dimensions were selected deliberately to yield 19 liters of pore space volume so that when a dose volume equivalent to the 14 liter pore space volume of the V10 filter was added to both filters it would represent approximately all of V10 pore space volume and three-quarters of the pore space volume of the FBSF. Both filters were later tested with 16 liters of influent which is approximately equivalent to the ratio of 
influent to pore space volume in the FBSF as 12 liters of influent is to the pore space volume of the V10 filter.

Each day for 25 days a mixture of Portage Canal water (a canal connecting Lake Superior to Portage Lake in Michigan) and raw sewage water was added to each of the filters which were setup side-by-side in a temperature controlled Michigan Technological University laboratory held at $28^{\circ} \mathrm{C}$. This time period was selected since previous studies have shown that a large part of filter development occurs in the first three weeks (Stauber, 2006). Since 12 liters is the maximum recommended dosage volume for the V10 filter and 16 liters is approaching its total pore volume, the volume of influent was varied between 12,14 , and 16 liters.

Since the filter development might act to increase microbial removal over time, thereby potentially diminishing or masking decreases in microbial removal due to increased dosage volumes, the dosages were increased in "mixed order", with 16, 12, and 14 liters being dosed on days 1, 9, and 25 respectively (Table 2). Samples were taken from the influents and effluents of both filters three times over the course of the experiment and tested for coliforms and E. coli in order to compare the percent reductions resulting from filtration between the two filters. Membrane filtration was used to measure the coliform and E. coli colony forming units (CFU) in $100 \mathrm{ml}$ grab-samples taken from the effluents of each filter. Membranes were saturated with two $\mathrm{ml}$ of m-coli Blue broth and incubated for 24 hours at $37^{\circ} \mathrm{C}$ in accordance with EPA lab method 10029 (EPA, 2003). Following incubation blue and red dots were counted as coliform colonies and blue dots as E. coli. 


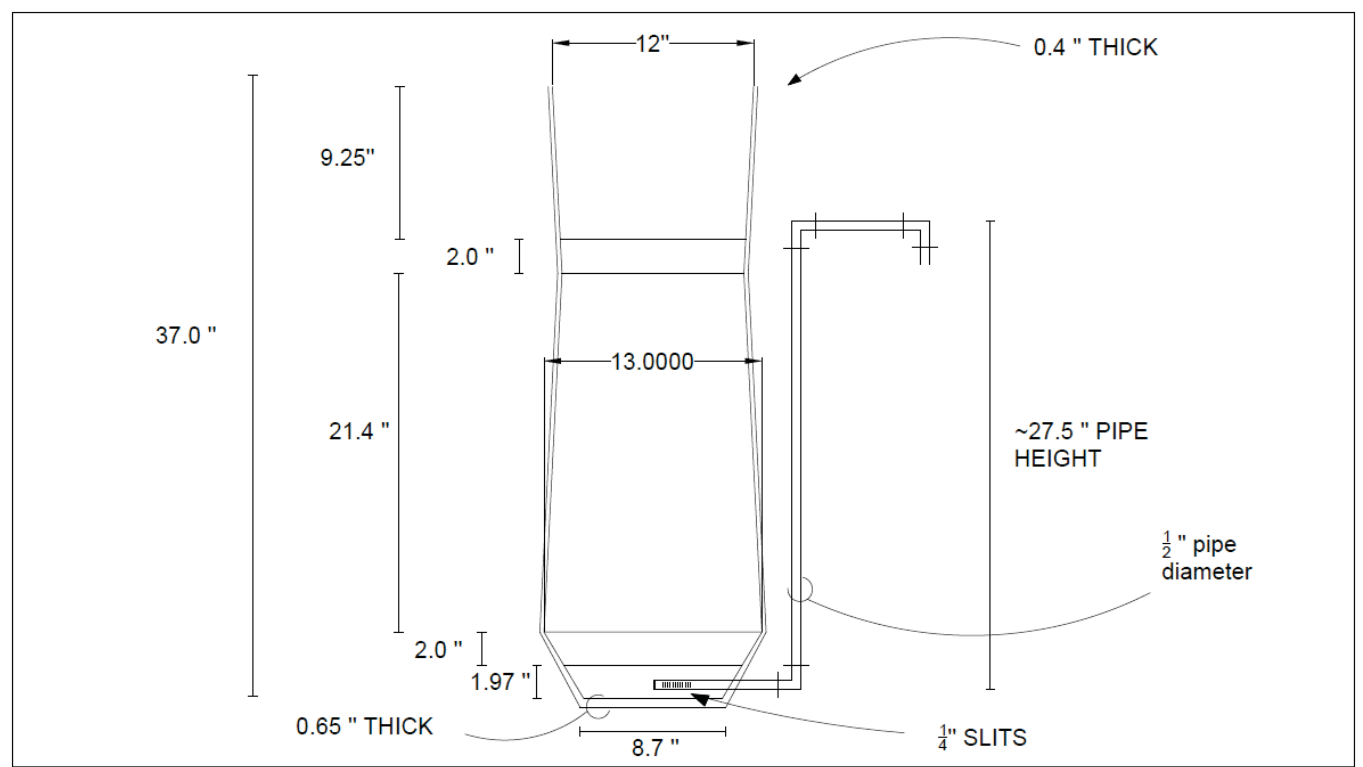

Figure 9. Schematic drawing of the enlarged FBSF used for this research. The body of this filter was expanded in diameter in order to yield a filter with greater capacity to store water between filtrations.

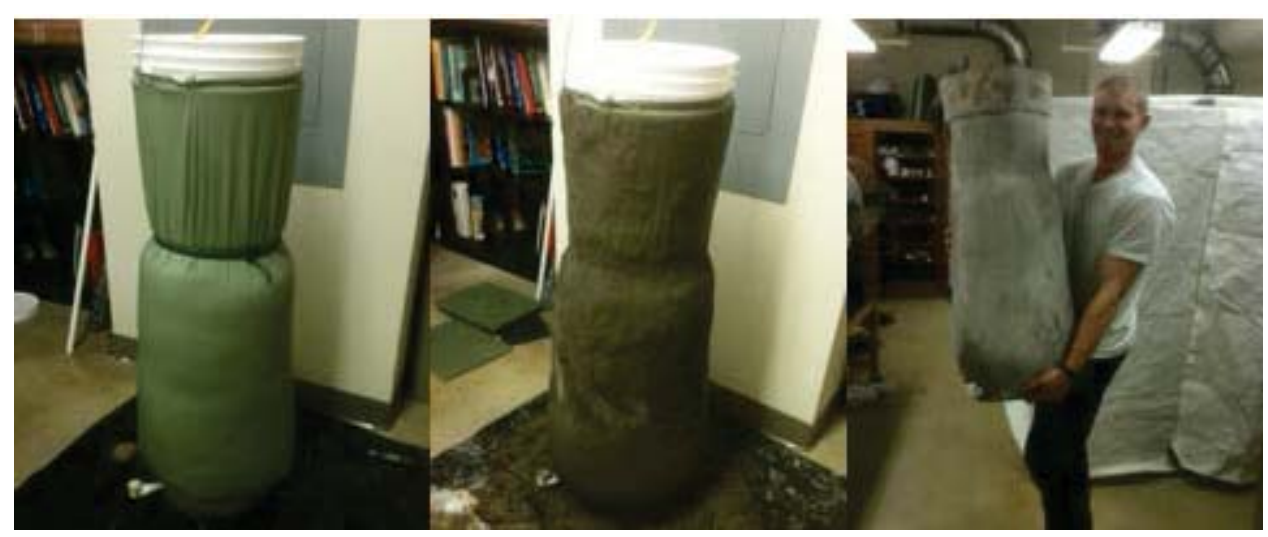

Figure 10. Process of enlarged FBSF construction. The three photos from left to right show the filled cloth mold, the first layer of cement, and the finished shell before the addition of sand, gravel, and the outlet tube. This filter was used alongside a plastic $\mathrm{V} 10$ model filter for comparison.

\subsection{Results of enlarged body investigation}

The results of the sieve test, for the sand only, is displayed as a grain size distribution curve (Figure 11) and inferred soil characteristics are given in Table 3. 


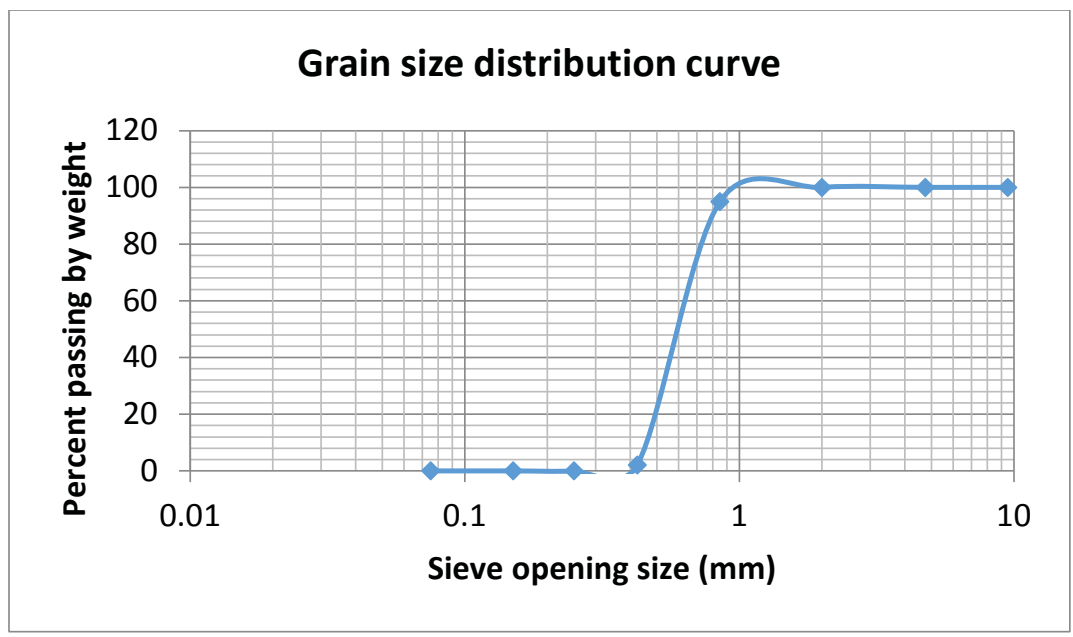

Figure 11. Particle size distribution (PSD) graph of sand media added to the model BSFs. For use in defining the uniformity and other qualities of the soil used. PSD should be tested and controlled for sand to be used in BSFs.

Table 3. The results of the enlarged filter body experiment including volume of influent, the test day, and percent removal of coliforms and E.coli. The V10 was a 17 L plastic filter. FBSF was a 19 L ferrocement filter.

\begin{tabular}{|l|l|l|l|l|l|}
\hline $\begin{array}{l}\text { Liters } \\
\text { influent }\end{array}$ & $\begin{array}{l}\text { Day of } \\
\text { experiment }\end{array}$ & V10 Col & V10 Ecoli & FBSF Col & FBSF Ecoli \\
\hline $\mathbf{1 2}$ & 9 & 96 & 95.5 & 97.3 & 98.875 \\
\hline $\mathbf{1 4}$ & 25 & 94.875 & 88.75 & 98.75 & 98 \\
\hline $\mathbf{1 6}$ & 1 & 83 & 71.91667 & 96.01667 & 95.58333 \\
\hline
\end{tabular}

When the maximum recommended dosage for the V10 filter of 12 liters was added to each filter, little to no difference was observed in removal abilities of the V10 filter and the FBSF. However, when the volume of the influent was increased to 14 and then to16 liters, filtration by the larger-bodied FBSF yielded significantly greater removal of coliforms and E. coli (Figures 11 and 12).

While some filter development most likely occurred during the experiment, it was effectively overshadowed by the effect of the increased dosage volumes. Table 2 shows the coliform and E. coli percent removals (out of chronological order). No significant 
positive trend appears between the number of days elapsed in the experiment and the removal percentages which would indicate a pronounced effect from filter development.

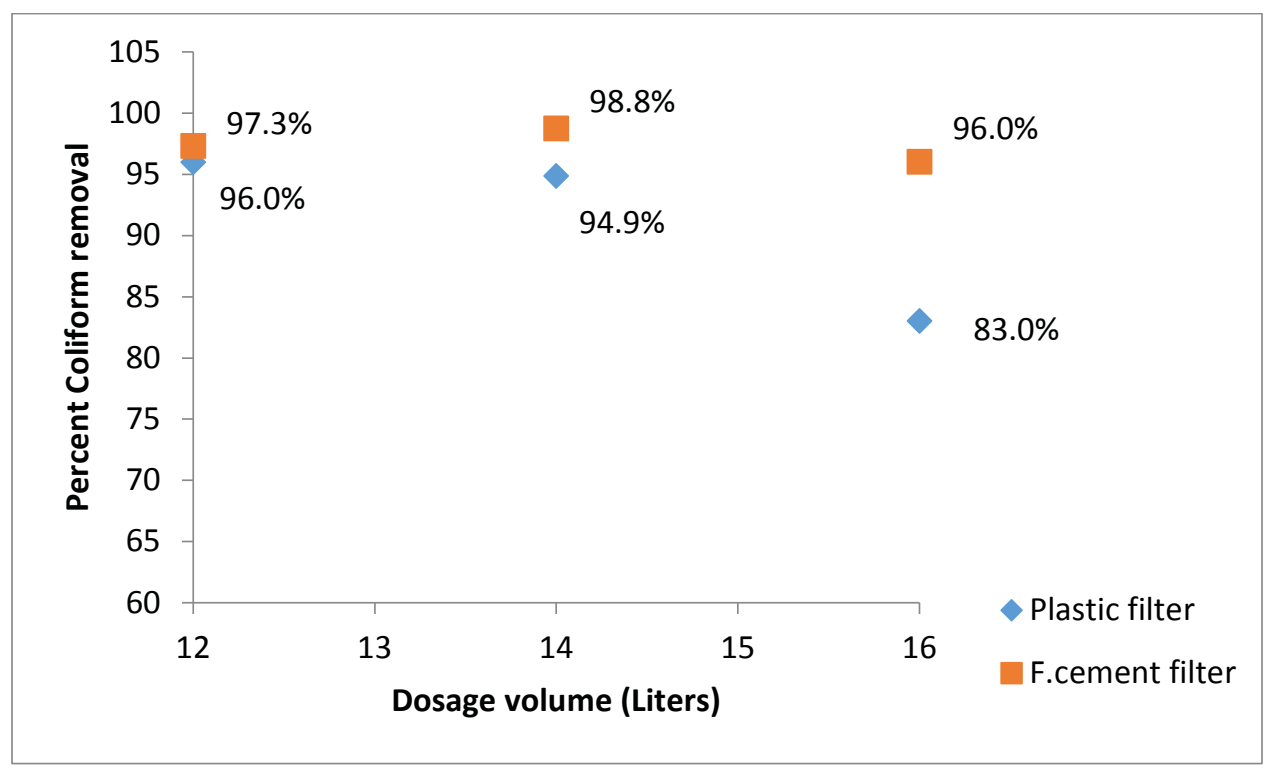

Figure 12. Coliform removal as a function of dosage volume of the enlarged FBSF and the V1O BSF. The percent removal appears to decline at different rates for the two filters as the dose volume is increased on separate days of the experiment.

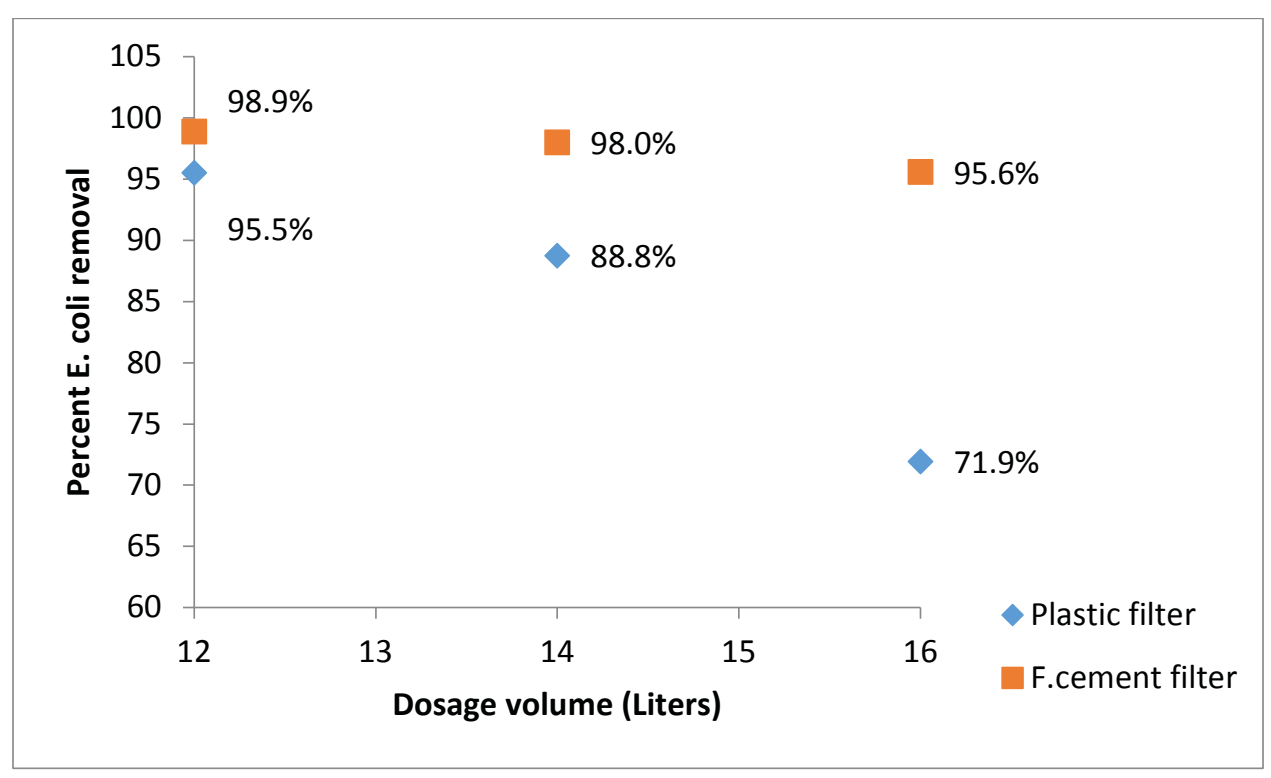

Figure 13. E.coli removal as a function of dosage volume of the enlarged FBSF and the V10 BSF. The percent removal appears to decline at different rates for the two filters as the dose volume is increased on separate days of the experiment. 


\subsection{Conclusions of enlarged body investigation}

The objective of this chapter was accomplished in that a larger body resulted in better contaminant removal for the same inflow volume when that volume exceeded 12 liters. The removal efficiency of the FBSF appeared unaffected by increasing the influent volume to 14 liters and only a small dip in performance was observed when 16 liters was added. From these results one might conclude that no more than 70 to $80 \%$ of a filter's pore space volume should be added to a filter as influent in a single day in order to avoid a drop in performance. This conclusion is also supported by the drops observed in the V10 filter removal efficiency as greater volumes of influent were added.

\subsection{Discussion of enlarged body investigation}

- Since results of the earlier described ferrocement investigation suggest that the removal percentages of coliforms and E. coli are comparable in water passed through plastic and ferrocement bodied filters of similar size, the differences in removal percentages between the V10 and FBSF used in this enlarged body investigation are not likely due to the filters' different construction materials. It is more likely that the observed difference in filter performance is due to the greater storage capacity within the FBSF. This greater capacity allows more water to be held for an extended idle period which has been shown to be critical to the quality of filter effluent. The V10 filter performed comparably to the FBSF up to 12 liters which supports the recommendation that this be the maximum dose volume that can be effectively treated by the V10 filter. If more treated effluent is 
desired by users then multiple filters or a filter with greater storage capacity should be considered for use.

The fact that the water quality declines when a volume greater than 12 liters is added to the V10 filter, despite the previously measured 14 liter pore space within the filter body, suggests that some mixing is occurring within the filter during dosing and that a perfect plug flow does not exist. This is supported by previous research by Elliot, et al. which described flow through the BSF as similar to a plug with a small amount of mixing (Elliot, 2008).

The trend between microbial removal and dosage volume could be used to predict the quality of the effluent given the amount of influent added for a filter with a known storage size. This is significant in the case of the FBSF since the mold can be tailored to yield essentially any body size desired. Thus construction could begin with a survey of the user(s) to find out how much clean water is needed in the home for each and the filter could be designed accordingly.

In this limited case study the V10 filter has been shown to be able to effectively deactivate coliforms and E.coli in a dose size which is roughly $70-80 \%$ of its total pore space volume. This information could be used to help in deciding the approximate dimensions of the body of a filter to be constructed for users with unique daily water demands. If a large family or multiple users intended to share a single filter it could be sized to hold roughly $125-143 \%$ of the families' actual water requirements within the filter body. 
One limitation of this large body FBSF study was that only a single large-bodied FBSF was compared to a single V10 BSF. If the findings of this study are to be confirmed future work should incorporate a greater number of filters of different sizes in order to rule out random inter-filter variations in performance.

FBSF construction, as described in the Appendix, is a much more time consuming process than the streamlined method of distributing plastic filter bodies or pouring cement shells using a mold. This remains a major hurdle for the mass construction and distribution of BSFs of specific sizes for each user or set of users. Without a faster method of construction the FBSF should not be seen as a replacement for the conventional BSF but rather an option for the knowledgeable individual who wishes to fabricate a relatively small number of filters for users with specific needs.

\section{Chapter 3: Temperature investigation}

\subsection{Introduction}

The objective of this section of research was to investigate the effect of temperature on the performance of the BSF. This effect was tested by varying the ambient temperatures within laboratories that housed separate groups of identical model sized filters.

Temperature is a variable which inevitably changes in the field depending on one's global location, elevation, season, and time of day. Given the anticipation of drastic changes in global temperatures due to climate change, the effect of temperature on the global burden of water related diseases has gained more attention as a topic of study in recent years (IPCCWG, 1998). 
Incidences of diarrhea tend to increase with temperatures suggesting that, within the livable temperature range, water-borne pathogens are more active in warmer water and that increases in diarrheal disease may accompany climate change (Singh, 2001). With an estimated 1.1 billion people lacking access to improved drinking water sources, an increase of water-borne pathogens has the potential to negatively affect a large percentage of the global population (WHO, 2000).

While much evidence exists to support the viability of the BSF as an effective POU water treatment technology in combating water borne pathogens, (Lenton et al., 2005, Sobsey, 2008), no research has tested its performance as a function of changing temperatures. Since BSFs are found in countries of warm, cold, and moderate climates, the effect of temperature is relevant to the BSF's usefulness in all locations. Further, an understanding of the BSF's performance as a function of temperature will help anticipate how its pathogen removing capabilities might be affected by the changing climate.

Some work in this area has been done using slow sand filters (SSF). The SSF operates very similarly to the BSF in that water is passed between small sand grains and pathogens are removed by way of physical trapping, biological predation within the filter, and adsorption (Aslan, 2007). The two filter types are, however, different in that the SSF is typically used to treat a constant flow of influent whereas the BSF receives influent intermittently. This difference has been shown to have a significant effect on the treatment capabilities of the two filter types (Young-Rojanschi, 2014).

One study seeking to measure the influence of different variables on the performance of the SSF determined that changing the temperature of a biologically mature filter had a 
significant initial effect on the filter's ability to remove coliforms as well as standard plate count bacteria, most likely due to its effect on the biological activity within the filter (Bellamy, 1985). In their study Bellamy et al. found that when matured filters, held at a temperature of $17^{\circ} \mathrm{C}$, were shifted to constant temperatures of $5^{\circ} \mathrm{C}$ and $2^{\circ} \mathrm{C}$ and then tested for coliform removal, 10 and 7.6 percent lower removal efficiency occurred respectively. While one would anticipate a similar temperature-removal relationship within the BSF, such a study has not been performed. Further, the temperature study by Bellamy et al. did not report the effect of temperature on sand filters over time and thus did not test the filter's ability to adapt as a biological system to the changes in temperature. Also, to see if pathogen removal is affected by changes in temperature following a predictable pattern, more temperatures are needed for comparison.

The objective of this study was to determine the effect of temperature on the BSF's ability to remove coliforms and E. coli. This was accomplished using four groups of three model sized filters in different temperature-controlled labs ranging from 4 to $30^{\circ} \mathrm{C}$ over the course of 66 days.

\subsection{Materials and methods of temperature investigation}

The bodies of $12 \mathrm{BSF}$ models were constructed using $2 \frac{1}{2}$ inch diameter PVC. In the vertical direction they were built identically to the most up-to-date BSF model, the Version 10 (V10) filter, according to the Center for Affordable Water and Sanitation Technology (CAWST) (CAWST, 2015) (Figures 13 and 14). The fill media was the same sand and gravel mixture previously described in Chapter 2. The bottom drainage gravel ranged in size from 12.5 to $6.35 \mathrm{~mm}$ in diameter and the smaller gravel directly beneath 
the sand was between 6.35 to $0.8 \mathrm{~mm}$. The filters were filled with distilled water before the media was added to avoid the trapping of air. Given an average measured media porosity of $47 \%$, as well as the interior volume of the exit pipe, and the two inches of standing water above the top layer of sand, the total volume of water stored in each filter between doses was estimated to be 1.2 liters.

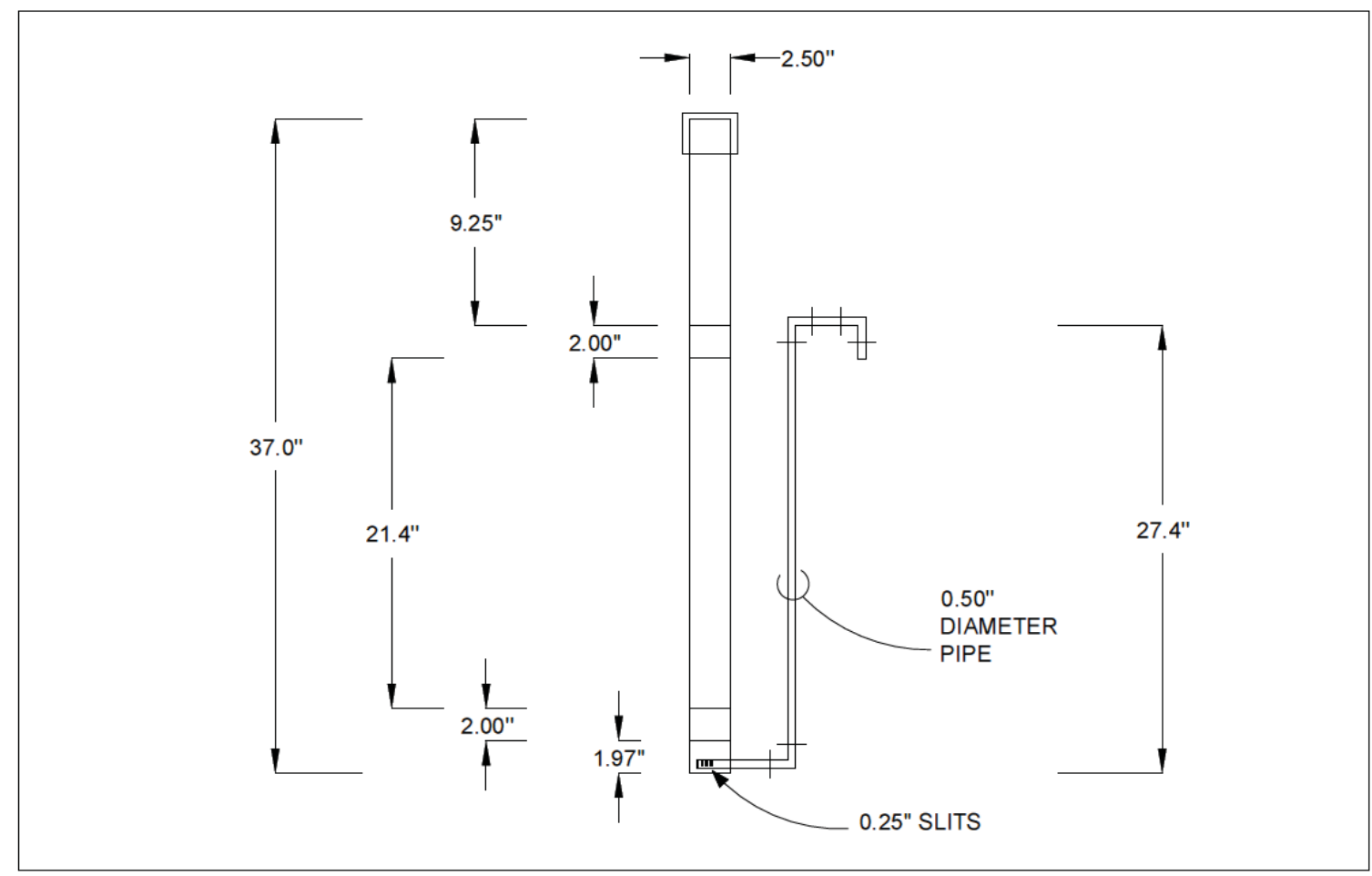

Figure 14. Schematic drawing of BSF model displaying dimensions. This model is vertically identical to the schematic given as Figure 1. Twelve identical filter models were constructed to these dimensions (drawing by author). 


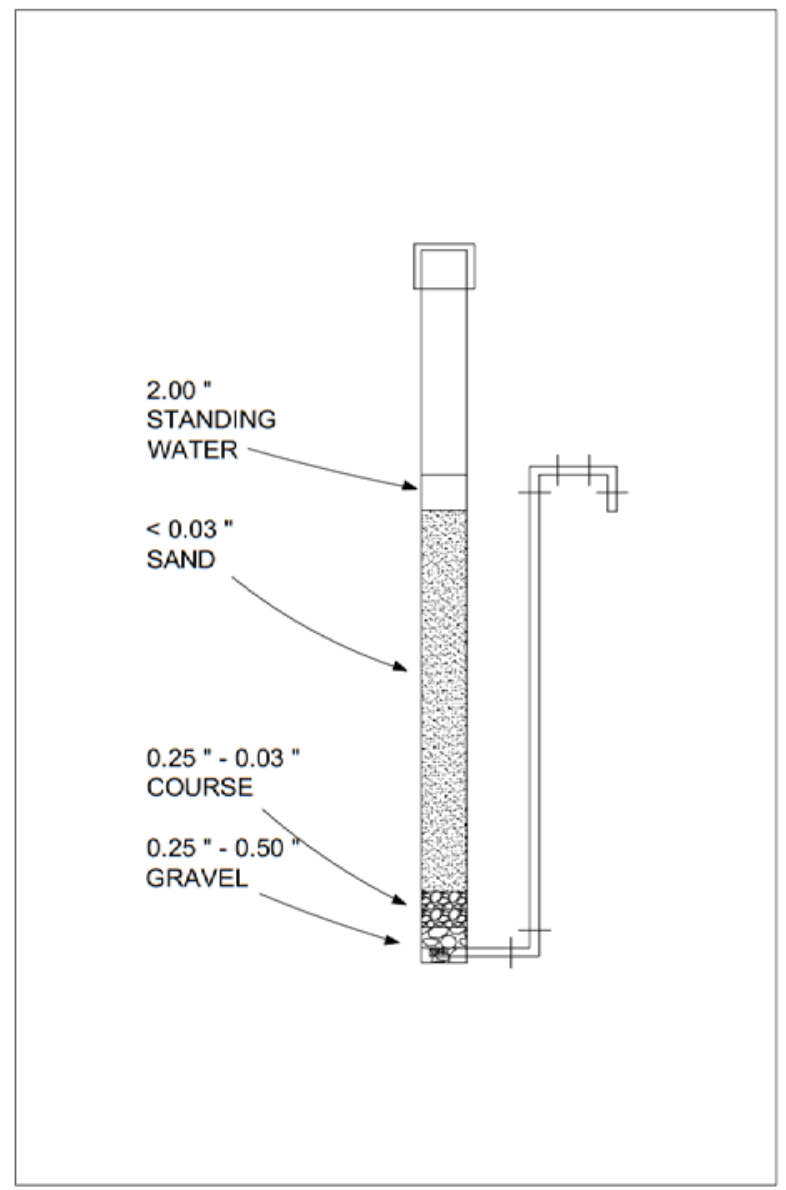

Figure 15. Schematic drawing of BSF displaying media sizes and order of layering. This model is vertically identical to the schematic given as Figure 2. Twelve identical filter models were constructed to these dimensions (drawing by author).

Table 4. Inferred characteristics of sand media added to the model BSFs.

\begin{tabular}{|c|c|c|}
\hline Parameter & Value & Units \\
\hline D60= & 0.62 & $\mathrm{~mm}$ \\
\hline D10 = & 0.45 & $\mathrm{~mm}$ \\
\hline Uniformity Coeff= & 1.38 & \\
\hline Dmax & 0.85 & $\mathrm{~mm}$ \\
\hline Silt content & $<2$ & $\%$ \\
\hline
\end{tabular}




\section{2 (a) Water used for dosing}

During the first 36 days of the experiment the filters were stored side-by-side in a lab held at $18^{\circ} \mathrm{C}$. The filters received daily one liter doses of water which was a mixture of local Portage Canal water (local fresh water river source) amended with raw sewage. Fourteen liters of fresh water was collected daily and a small portion of raw sewage ranging from $0.25 \mathrm{ml}$ to $5 \mathrm{ml}$ was added immediately before dosing, after the river water had reached $18^{\circ} \mathrm{C}$. The mixture was stirred vigorously for three minutes prior to dosing the filters.

\section{2 (b) Water quality testing}

Throughout the 66 day experiment filters were tested 14 times for total coliform and E. coli removal and eight times for turbidity and flow rate. A Hach 2100P portable turbidity meter was used to measure the turbidity of the filters' influents and effluents (Hach, 2015). Flow rate was measured as the time it took for the first $100 \mathrm{ml}$ to exit the filter. This volume was chosen somewhat arbitrarily since the flow rate through the BSF continuously decreases as the water level above the exit pipe drops.

As described in the previous chapter, membrane filtration was used to measure the coliform and E. coli colony forming units (CFU) in $100 \mathrm{ml}$ grab-samples taken from the one liter effluents of each filter in accordance with EPA lab method 10029 (EPA, 2003). Filter influent water was tested 24 hours before the effluent to account for the storage capacity of the filters. The same influent water was retested 24 hours later along with the filter effluents in order to account for natural die-off over time. This was done since water running through the filter resembles a plug flow so that the first water to leave the filter 
during dosing is the water from the previous day's dose (Elliot, 2008). Only after the volume of effluent exceeds the filter's storage capacity does newly added water begin to leave the filter as effluent. Since a 24 hour storage time has been shown to reduce pathogens in the effluent, it is recommended that users do not add a dose volume greater than the filter's storage capacity in a single day (Elliot 2011).

Following the first 36 days of testing at constant temperatures the filters were randomly separated into four groups of three and placed in labs held at the temperatures of $4,12,18$, and $27^{\circ} \mathrm{C}$. These temperatures were selected because they relatively evenly span the temperatures ranging from just above freezing to the warmest laboratory setting available to the MTU environmental engineering and biological sciences departments which was $27^{\circ} \mathrm{C}$. To ensure random grouping, each of the twelve filters was assigned a number which was written on a slip of paper and placed in a hat. Their room placement followed from the order in which they were drawn from warmest to coldest.

In the temperature-controlled labs the filters continued to be dosed daily with the same fresh water/sewage mixture and were tested weekly for 30 days. Including the first 36 days of the experiment, a total of 66 liters of water passed through each of the twelve filters during the experiment.

In addition, preliminary experiments were performed examining the effect of temporary freezing on removal efficiencies of a number of the BSF models. On day 64 of the experiment two filters from each of the four temperature-controlled labs (eight of the twelve filters) were randomly chosen to be frozen for ten hours and then thawed simulating a cold to extremely cold night in the field. Four of the eight selected filters were frozen at 
a temperature of $-1{ }^{\circ} \mathrm{C}$ while the four others were frozen at $-22^{\circ} \mathrm{C}$. These temperatures were selected to represent both a superficial and a complete freeze respectively. All eight of the filters selected for freezing were then placed back in the labs from which they had been removed and allowed to thaw for 24 hours before being tested. The filters that were not selected for freezing were held in their respective temperature labs as controls.

\subsection{Results of temperature investigation}

The average turbidity of the influent mixture of portage water and sewage was 1.71 NTU with a standard deviation of $0.18 \%$. The average percent reduction observed following filtration was $29.8 \%$ with a standard deviation of $7.7 \%$. The average flow rate throughout the experiment was $71.1 \mathrm{ml} / \mathrm{min}$ with a standard deviation of 8.45 .

After 48 hours in the temperature-controlled labs the filters were tested for coliform and E.coli removal the results of which, along with the results from the previous week's tests, are given in Figures 16 and 17. 


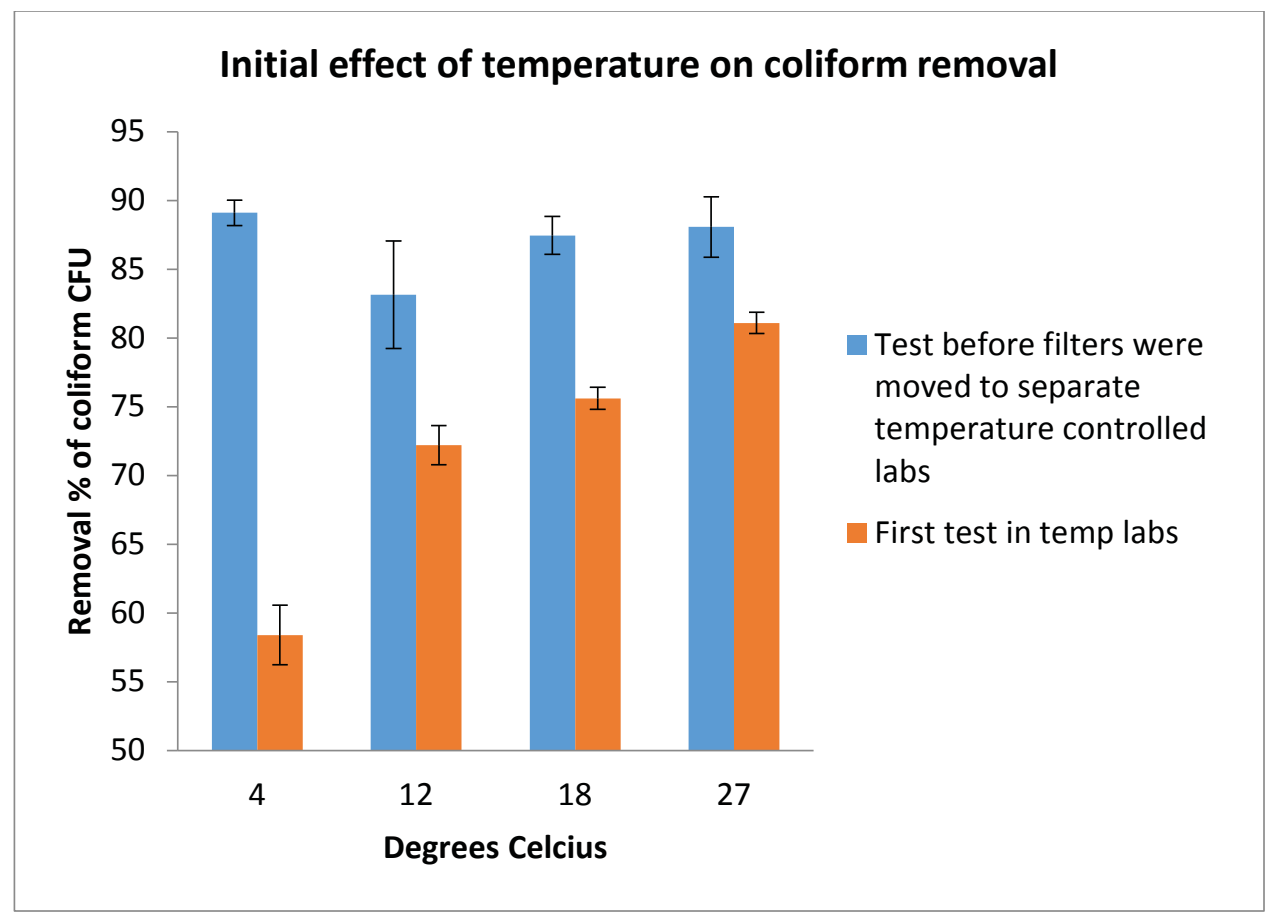

Figure 16. Percent coliform removal of filters exposed to different ambient temperatures. The results of the first test following initial temperature changes are shown in orange alongside the results from the previous test (prior to treatment with different temperatures) in blue. Error bars calculated as $+/$ - the standard deviation divided by the square root of the number of samples.

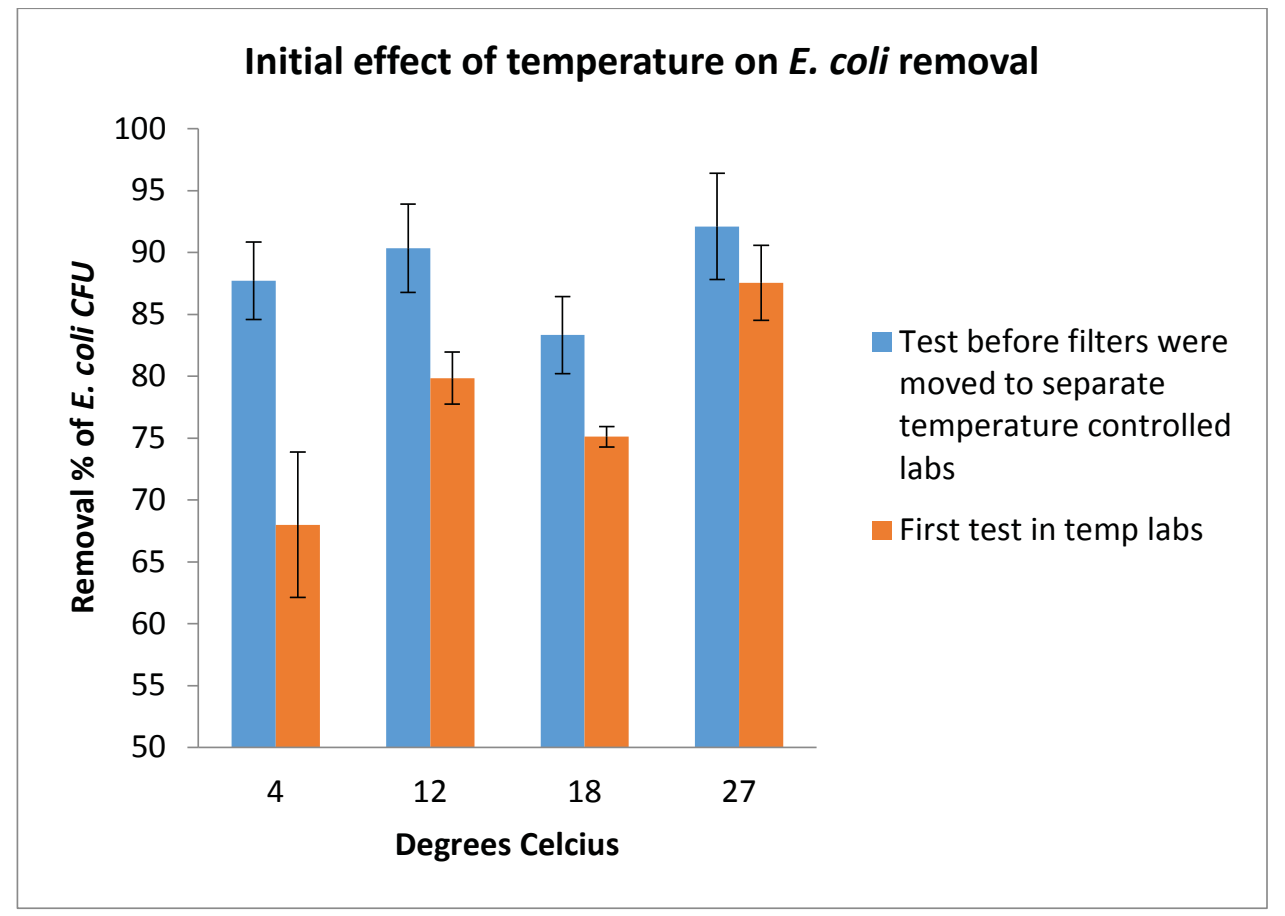

Figure 17. Percent E.coli removal of filters exposed to different ambient temperatures. The results of the first test following initial temperature changes are shown in orange alongside the results from the previous test (prior to treatment with different temperatures) in blue. Error bars calculated as $+/-$ the standard deviation divided by the squar root of the number of samples. 
Filters remained in their separate temperature labs for the final 30 days of the 66 day experiment during which time samples were tested for bacterial removal every three to seven days. The results from those tests, as well as from the first 36 days prior to separation, are given in Figure 18. In the first test immediately following separation into temperature controlled labs, a significant dip in coliform and $E$. coli removal was observed in the filters placed in colder labs. 16 days later, however, those filters had increased their removal until they matched the removal efficiencies of filters held in warmer rooms (Figures 19 and 20). Results from the final test following the freeze/thaw treatment are given in Figures 21 and 22.

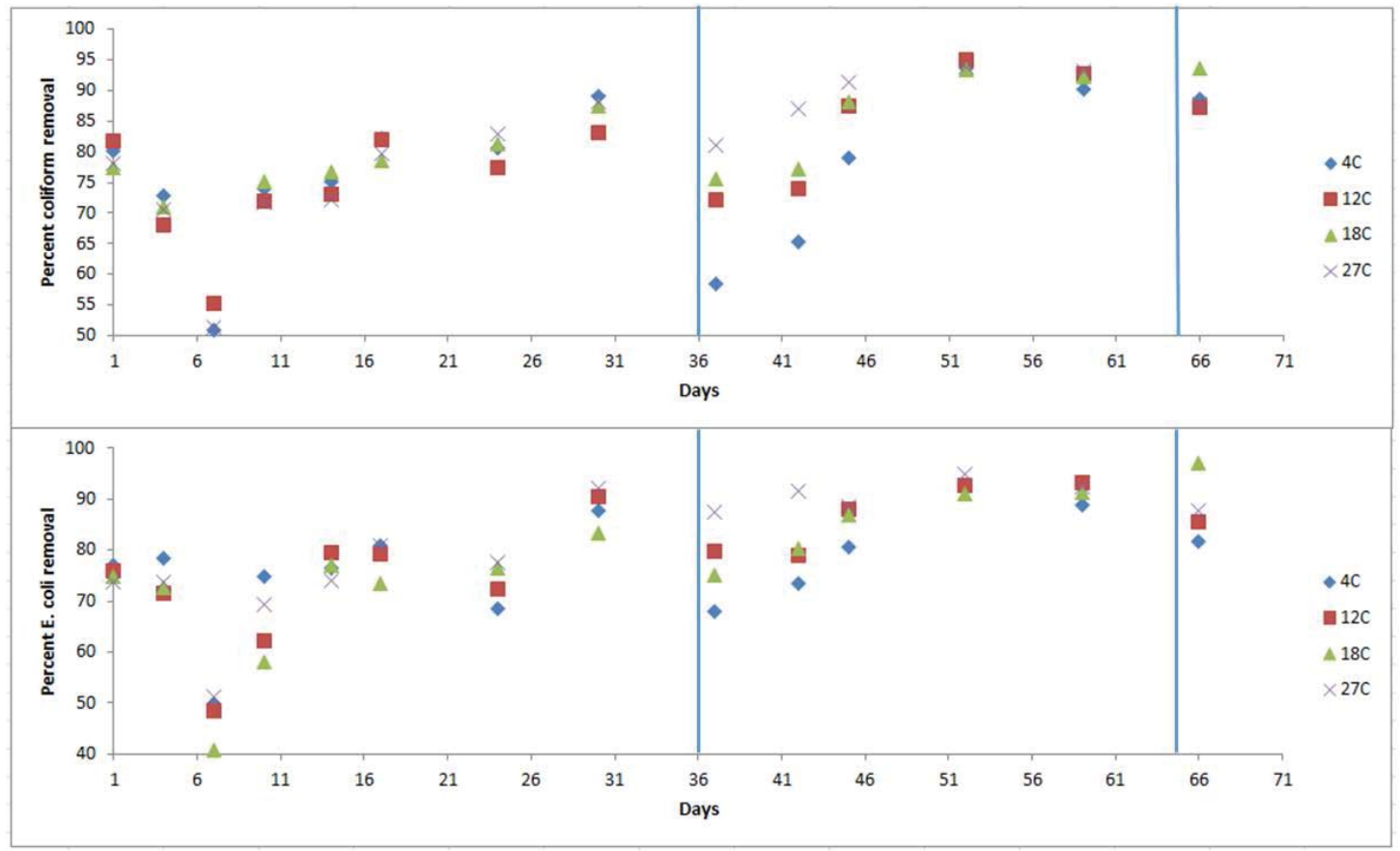

Figure 18. Percent removal of coliforms and E.coli as a function of the time elapsed in the experiment. Blue lines encapsulate the window of time in which filters were held in separate temperature controlled labs (days 36 to 66). Before day 36 filters were all held at 18 degrees $C$. The final test on day 66 included only one filter in each controlled lab while eight of the filters were frozen. 


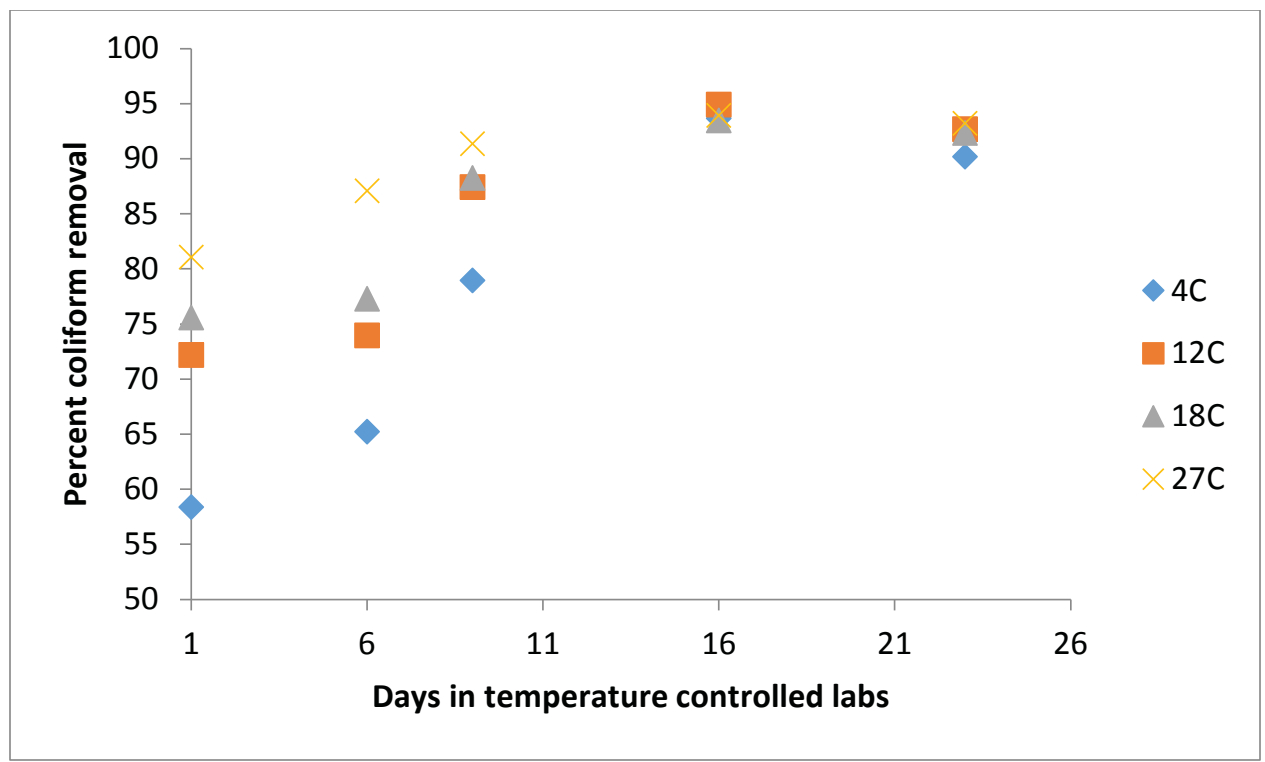

Figure 19. Percent coliform removal over time during portion of experiment with filters in temperature controlled labs. This data is also shown in Figure 18 as the portion between the vertical blue lines.

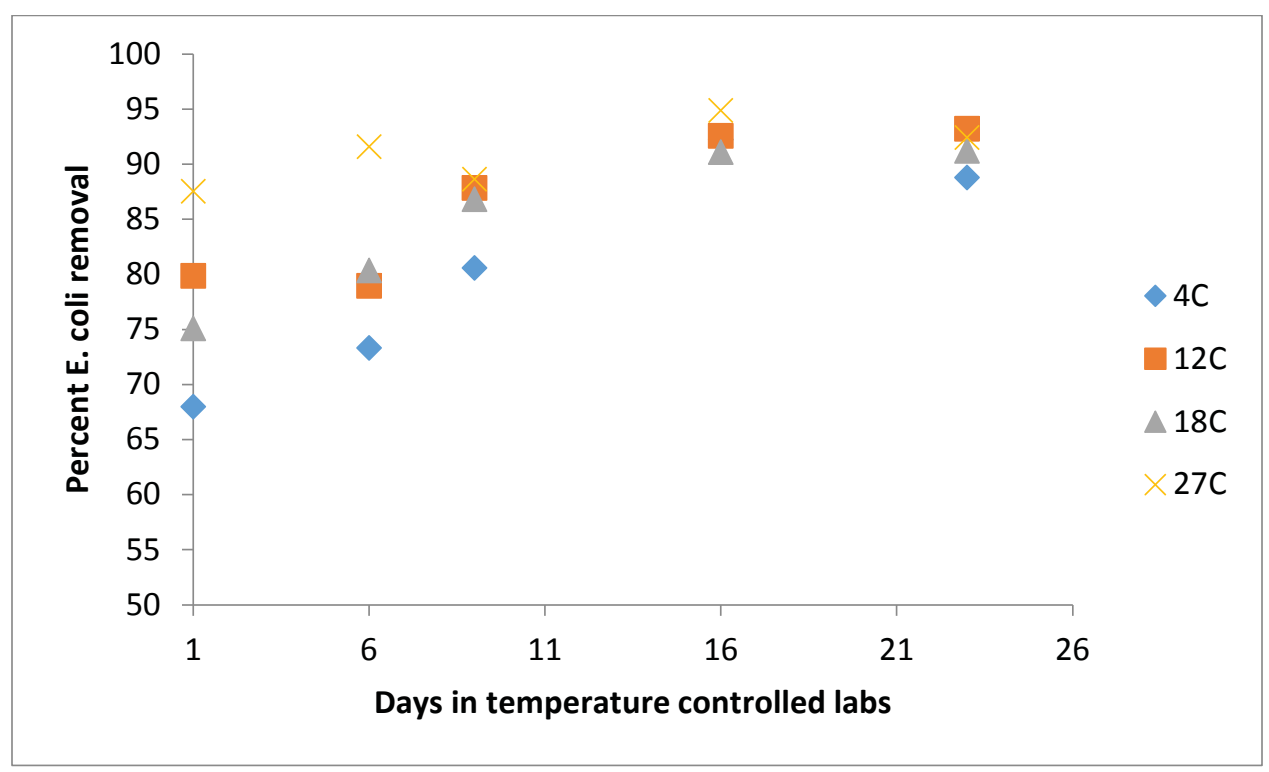

Figure 20. Percent E.coli removal over time during portion of experiment with filters in temperature controlled labs. This data is also shown in Figure 18 as the portion between the vertical blue lines. 


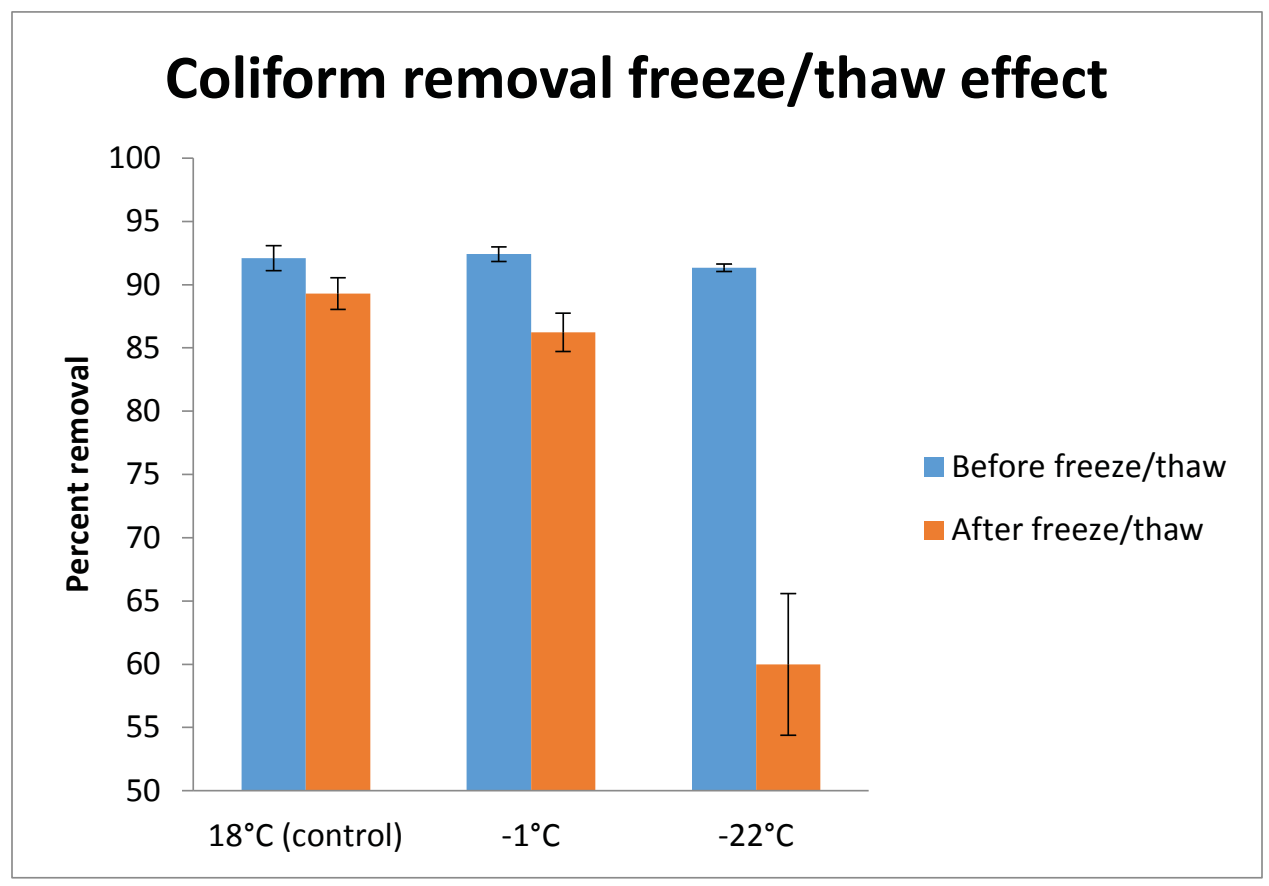

Figure 21. Coliform reduction in filters following freeze/thaw treatment at different temperatures. Error bars calculated as + - the standard deviation divided by the square root of the number of samples.

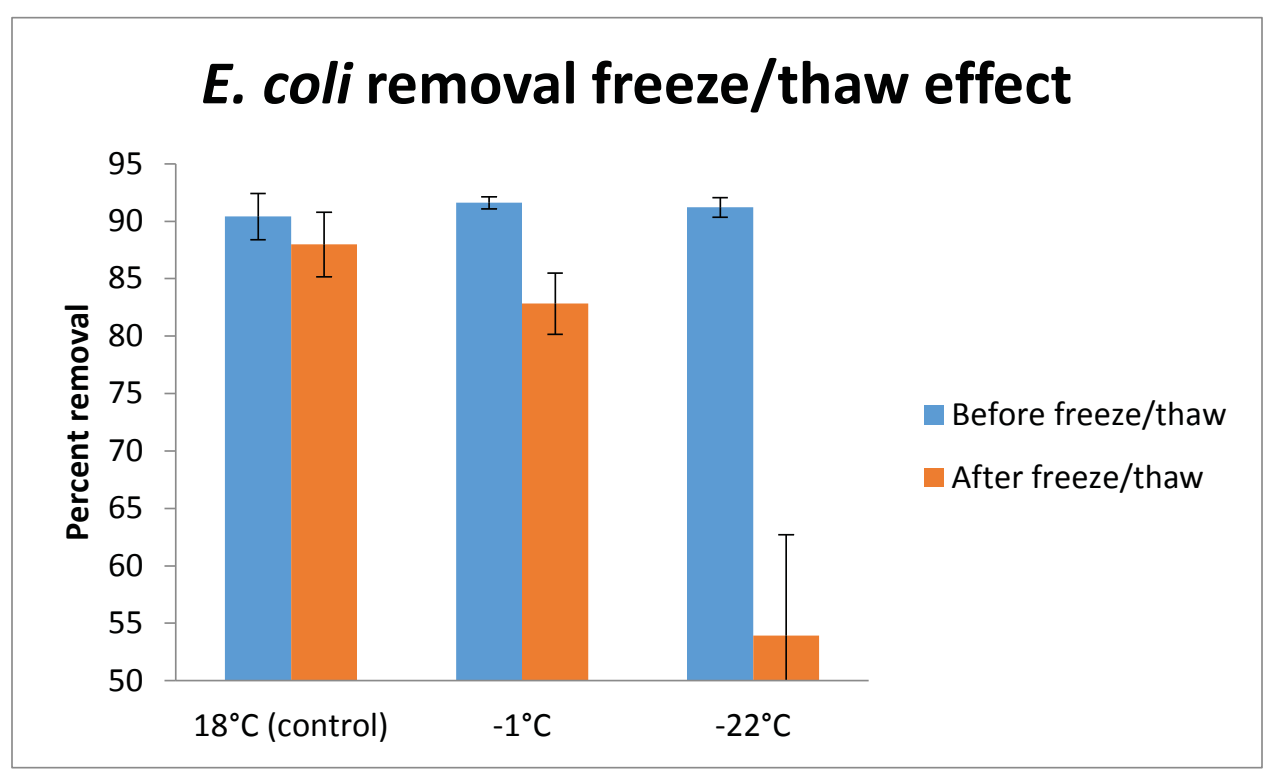

Figure 22. E.coli reduction in filters following freeze/thaw treatment at different temperatures. Error bars calculated as $+/$ - the standard deviation divided by the square root of the number of samples. 


\subsection{Conclusions of temperature investigation}

The objective of this chapter was accomplished in that it was shown that temperature has an initial effect on contaminant removal but over time the removal is similar no matter which temperature the filters operate at. Further, deep freezing initially diminishes the performance significantly.

On average, the ability of BSFs to remove the tested microbial species was initially decreased by exposure to colder temperatures (Figure 21). Over time, however, when held at constant cold temperatures for extended periods, these filters showed the ability to sufficiently adapt until they matched the removal percentages of filters held at warmer temperatures. While similar initial changes in filter performance following ambient temperature changes had been observed in SSFs, the ability to rebound from the initially deleterious effects of altered temperatures had not been previously documented. The rebound time of roughly 16 days in filters used daily implies that BSFs most likely would have the ability to adapt to seasonal and climactic temperature changes which tend to occur more gradually than the temperature the changes in this experiment. These findings helped meet the objective of determining ideal installation conditions for BSFs in the field. Based on the results BSFs have the ability to adapt and perform well when exposed to a large range of temperatures and the climate of a specific geological location should not be considered a major factor when deciding whether BSF installation is appropriate.

Further, the superficial or complete freezing of BSFs did seem to have a negative effect on the bacterial removal efficiencies of the filters tested. While one might assume 
the performance of the filter would rebound from temporary freezing events, in order to avoid negative fluctuations in filter performance users should install filters indoors where freezing temperatures occur regularly. This is especially important where temperatures are cold enough to completely freeze BSFs since the negative effects on filter performance were shown to be far more drastic in the cases of solid freezing.

\subsection{Discussion of temperature investigation}

The observable trend of improvement in filters held at colder temperatures indicates that filters installed in colder climates would have the ability to develop and achieve similar removal percentages as filters installed in warmer environments. Whether or not development would occur at the same rate for filters installed in warm and cold climates is beyond the scope of this study but could be easily investigated by testing newly assembled filter models in different temperature controlled labs.

The freezing of a BSF does appear to have an immediately negative effect on that filter's ability to remove coliforms and E.coli from water even after thawing and returning the filter to its original temperature. Therefore in field locations with freezing temperatures it might be advantageous to install filters inside the home in order to buffer colder, usually night time, fluxes in temperatures. If a filter does become frozen the user should expect temporarily below average performance. They could compensate for this effect by incorporating secondary water treatment prior to drinking until the filter had sufficient time to recover.

The damage to the filter's performance seemed to vary depending on the temperature of the freeze. Moderate freezing events such as simulated by the $-1{ }^{\circ} \mathrm{C}$ 
treatment, where the filter does not freeze solidly, seem to have a much slighter effect than when filters became solidly frozen at $-22^{\circ} \mathrm{C}$. In the latter case the bodies of two of the filter models involved in the experiment cracked due to water expansion and were no longer usable. The removal percentages of all remaining filters following this treatment were significantly worsened (Figures 18 and 19). Luckily a freezing event this damaging is very unlikely in the field. While filters seem to effectively rebound in their abilities to remove microbes when exposed to consistently colder temperatures, it is unlikely that this would be the case when temperatures frequently dipped below freezing. In such environments, it is advisable that users keep their filters indoors where temperature changes may be buffered.

\section{Discussion of the three sections}

Significant findings from the three studies are numbered corresponding to their chapter above: 1) FBSFs performed comparably to plastic and cement BSFs in the field indicating that the future use of this construction technique is a reasonable option under certain field conditions, 2) an enlarged bodied filter can perform optimally even as influent volumes are increased beyond the recommended dose for a conventionally sized BSF which suggests that the body-size of a filter could be tailored specifically to the users'

needs, and 3) and while changing the ambient temperature can affect the BSF's ability to remove coliforms and E.coli from filtered water, the BSF will return to peak performance over time most likely due to the adaptation of the live biological community within the filter body. 
In the future, more research will be needed to test a greater number of FBSFs in the field. While this research showed a difference between the quality of filtered and unfiltered water, the sample size was not large enough to achieve normally distributed data. Similarly, a comparative test between greater numbers of filters of differing body sizes is needed to legitimize the claim that ideal body size can be predicted based on the needs of potential users. In this study only a single enlarged FBSF was compared to a single plastic V10 filter which is not sufficient to claim significant results. Finally, an experiment which allows identical filters to develop at different temperatures would answer the question of whether the rate of initial filter development is affected by ambient temperatures. This would be useful knowledge for individuals installing filters in different climates as they would know approximately how long to wait for their filters to fully develop.

The combination of the three investigations included in this thesis help to advance the available knowledge of the construction, sizing, and installation of BSF in the field. 


\section{References}

$3 \mathrm{M}^{\mathrm{TM}}$ Food Safety Website - Product Catalog: $3 \mathrm{M}^{\mathrm{TM}}$ Petrifilm ${ }^{\mathrm{TM}}$ E.coli/Coliform Count Plates. $2015 . \quad$ Accessed February 10.http://solutions.3m.com/wps/portal/3M/en_US/Microbiology/FoodSafety/prod uct-information/productcatalog/?PC Z7_RJH9U523003DC023S7P92O3087000000 nid=C0WJ62882Vb e29BDXSBJ7Fgl.

Annette Prüss-Üstün, Robert Bos, and Jamie Bartram Fiona Gore. 2008.Safer Water, Better Health: Costs, Benefits and Sustainability of Interventions to Protect and Promote Health. Online 1. Spain: World Health Organization (WHO).http://whqlibdoc.who.int/publications/2008/9789241596435 eng.pdf.

Aslan, Sukru, and Hatice Cakici. 2007. "Biological Denitrification of Drinking Water in a Slow Sand Filter." Journal of Hazardous Materials148 (1-2): 253-58. doi:10.1016/i.jhazmat.2007.02.012.

Bellamy, W. D., D. W. Hendricks, and G. S. Logsdon. 1985. "Slow Sand Filtration: Influences of Selected Process Variables."Journal - American Water Works Association $77 \quad$ (12): 66. http://cat.inist.fr/?aModele=afficheN\&cpsidt=8580351.

CAWST. 2015. "CAWST Center for Affordable Water and Sanitation Technology". Charitable foundation.CAWST Center for Affordable Water and Sanitation Technology.http://www.cawst.org/index.php.

Duke, WF. 2006. "The Use and Performance of BioSand Filters in Artibonite Valley of Haiti: A Field Study of 107 Households." The International Electronic Journal of Rural and Remote Health Research, Education, Practice and Policy 6 (1445-6354): 570.

Elliott, M. A., C. E. Stauber, F. Koksal, F. A. DiGiano, and M. D. Sobsey. 2008. "Reductions of E. Coli, Echovirus Type 12 and Bacteriophages in an Intermittently Operated Household-Scale Slow Sand Filter.” Water Research 42 (10-11): 266270. doi:10.1016/j.watres.2008.01.016.

Elliott, M. A., F. A. DiGiano, and M. D. Sobsey. 2011. "Virus Attenuation by Microbial Mechanisms during the Idle Time of a Household Slow Sand Filter." Water Research 45 (14): 4092-4102. doi:10.1016/j.watres.2011.05.008.

EPA. 2003. "United States Environmental Protection Agnecy". http://www.epa.gov/ogwdw/disinfection/lt2/pdfs/guide_lt2_mlmanual_appendixo.pdf. 
Fiore, M.M. 2010. “Assessment of Biosand Filter Performance in Rural Communities in Southern Coastal Nicaragua: An Evaluation of 199 Households." The International Electronic Journal of Rural and Remote Health Research, Education, Practice and Policy 10 (1483).

First Net Impressions LLC. 2015. "Red Flint Sand and Gravel”. Business.Red Flint Sand and Gravel, Naturally Clean. http://www.redflint.com/.

Galina Reshes. 2007. “Cell Shape Dynamics in Escherichia Coli.” Biophysical Journal 94 (1): 251-64.http://www.ncbi.nlm.nih.gov/pmc/articles/PMC2134870/.

Gimbel, Rolf, Nigel Jonathon Douglas Graham, and M. Robin Collins. 2006.Recent Progress in Slow Sand and Alternative Biofiltration Processes (pg 275). IWA Publishing.

Hach Company. 2015. "Hach. Ensuring Water Quality for People around the World". Business. Hach.http://www.hach.com/.

II, Intergovernmental Panel on Climate Change Working Group (IPCCWG). 1998. The Regional Impacts of Climate Change: An Assessment of Vulnerability. Cambridge University Press.

Lenton, R. L., Albert Morgan Wright, and Kristen Lewis. 2005. Health, Dignity and Development: What Will It Take? Earthscan.

Organization, World Health, and International Network to Promote Household Water Treatment and Safe Storage. 2007. "Combating waterborne disease at the household level."http://apps.who.int//iris/handle/10665/43621.

Rosa-lee Cooke. 2000. "Water/Wastewater Distance Learning Website." Educational. Water/Wastewater Distance Learning Website.http://water.me.vccs.edu/.

S.P. Shah. 1981 n.d. "Ferrocement in Construction." The Aberdeen Group.

Singh, R B, S Hales, N de Wet, R Raj, M Hearnden, and P Weinstein. 2001. "The Influence of Climate Variation and Change on Diarrheal Disease in the Pacific Islands." Environmental Health Perspectives $109 \quad$ (2): 15559. http://www.ncbi.nlm.nih.gov/pmc/articles/PMC1240636/.

Sobsey, Mark D., Christine E. Stauber, Lisa M. Casanova, Joseph M. Brown, and Mark A. Elliott. 2008. "Point of Use Household Drinking Water Filtration: A Practical, Effective Solution for Providing Sustained Access to Safe Drinking Water in the Developing World."Environmental Science \& Technology 42 (12): 4261-67. doi:10.1021/es702746n. 
Stauber C.E. 2006. "Characterisation of the Biosand Filter for E. Coli Reductions from Household Drinking Water under Controlled Laboratory and Field Use Conditions."Water Science and Technology 54 (3): 1-7.

Stauber, Christine E., Gloria M. Ortiz, Dana P. Loomis, and Mark D. Sobsey. 2009. "A Randomized Controlled Trial of the Concrete Biosand Filter and Its Impact on Diarrheal Disease in Bonao, Dominican Republic." The American Journal of Tropical Medicine and Hygiene $80 \quad$ (2): 28693. http://www.ajtmh.org/content/80/2/286.

Suleiman, Mohd Zailan, Roslan Talib, and Mahyuddin Ramli. 2013. "Durability and Flexibility Characteristics of Latex Modified Ferrocement in Structural Development Applications." Journal of Engineering, Design and Technology 11 (1): 59-70. doi:http://dx.doi.org/10.1108/17260531311309134.

Surendra P. Shah. 1991. "Do Fibers Increase the Tensile Strength of Cement-Based Matrix?" Materials Journal88 (6): 595-602.

Tiwari, Sangya-Sangam K., Wolf-Peter Schmidt, Jeannie Darby, Z. G. Kariuki, and Marion W. Jenkins. 2009. "Intermittent Slow Sand Filtration for Preventing Diarrhoea among Children in Kenyan Households Using Unimproved Water Sources: Randomized Controlled Trial.” Tropical Medicine \& International Health 14 (11): 1374-82. doi:10.1111/j.1365-3156.2009.02381.x.

Triple Quest. n.d. 2015. “Triple Quest”. Business. Triple Quest Hydraid Biosand Water Filter.http://www.hydraid.org/.

US EPA, Office of Web Communications and Office of Environmental Information. 2015. "Point of Use (POU) Technologies| Radionuclides Decision Tree| US EPA." Accessed

February 27.http://cfpub.epa.gov/safewater/radionuclides/radionuclides.cfm?action=Rad_P oint $\% 20$ of $\% 20$ Use.

Weber-Shirk, Monroe L., and Richard I. Dick. 1997. "Physical-Chemical Mechanisms in Slow Sand Filters." American Water Works Association. Journal 89 (1): 87. http://search.proquest.com/docview/221579542?pq-origsite=gscholar.

WHO | Guidelines for Drinking-Water Quality, Fourth Edition 2011. 2015.WHO. Accessed February 14.http://www.who.int/water sanitation health/publications/2011/dwq chapters/e n/.

WHO | Managing Water in the Home. 2015. WHO. Accessed February 15.http://www.who.int/water_sanitation_health/dwq/wsh0207/en/index5.html.

Wikimedia. 2015. "File:Panama-Map-Blank.png." Creative Commons.Wikimedia Commons.https://commons.wikimedia.org/wiki/File:Panama-map-blank.png. 
World Health Organization, UNICEF, and Water Supply and Sanitation Collaborative Council. 2000. Global Water Supply and Sanitation Assessment 2000 Report. New York, New York.

Young-Rojanschi, Candice, and Chandra Madramootoo. 2014. "Intermittent versus Continuous Operation of Biosand Filters." Water Research 49 (February): 1-10. doi:10.1016/j.watres.2013.11.011. 


\section{Appendix A - Ferrocement Biosand Filter Building Instructions}

\section{Ferrocement biosand filter}

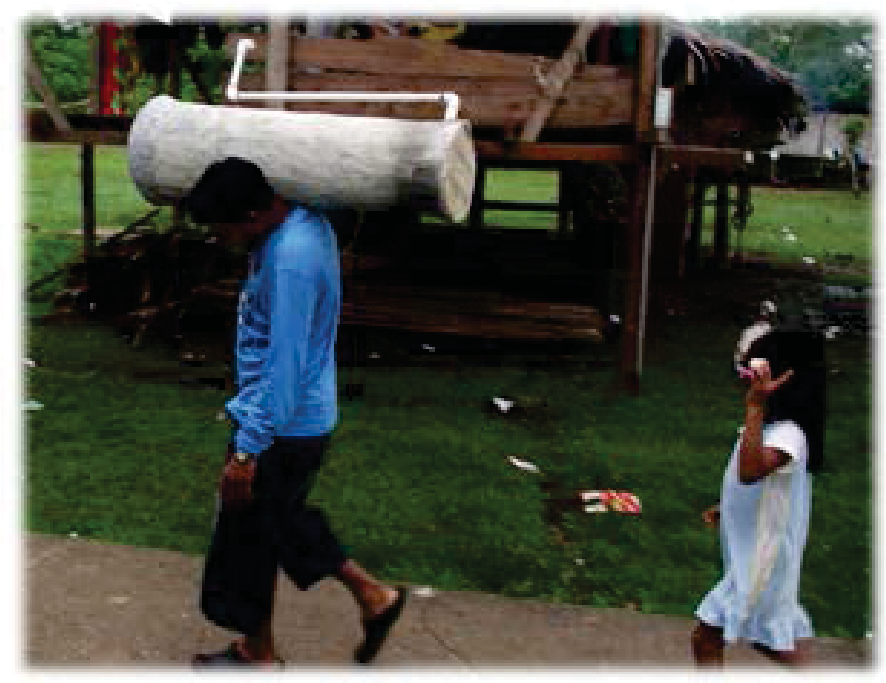

\section{Building instructions}

A. The cover page of the ferrocement BSF building instructions used for this research.

\section{1) Separate sand}

\section{and gravel.}

To separate sand and gravel of the three necessary sizesyou'll need three sieves and a good source of sand/gravel. An ideal source is crushed rock from a quarry but where one isn't available sand/gravel can be found near rivers. Sand found directly in rivers isn't ideal since the grains tend to be too smooth. Never use beach sand since it contains salt and avoid grain sizes that are too small such as clay or silt since water will not passthrough. Designyour sieves to yield the three sizes shown in Figure $B$. You'llneed at least four buckets of the smallest grain since it will be used for cement mixing as wellas to fillthe majority of the filter. You'llneed about a quarter bucket of the two larger sizes shown in Figure B.

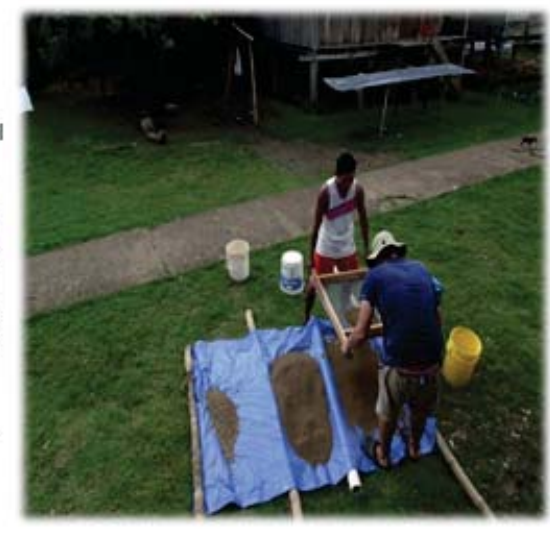

B. Instructions and photo to aid in sand sieving. 


\section{2) Make the form out}

of six pieces of cloth.

The pieces can vary in size depending on the size of the final form you're shooting for. Leave an extra inch on each edge so that you can sew them together. Don't sew the top edges together but fold over the extracloth at the top of each side paneland sew a little pocket for a drawstring to pull the bag tight. Once sewn together, partially pack the form with a dried materia like rice husk, grassclippings, or saw dust. Dimensions in photo are only given as

example. Sewn, filled bag is shown in later slide.

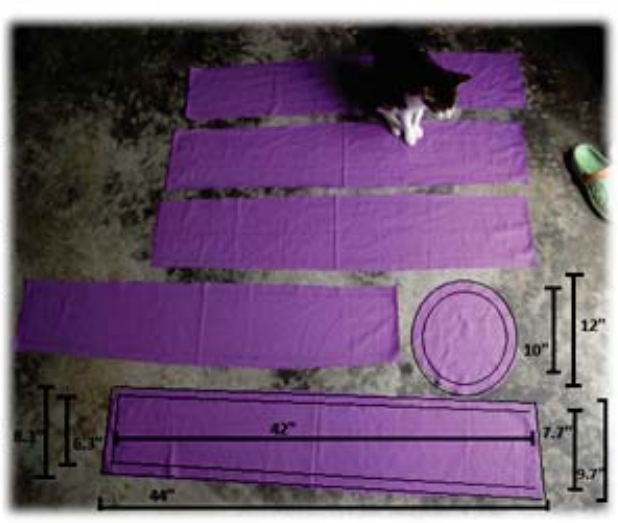

C. Instructions and photo to aid in tailoring the form.

3) Make a mold for the base out of 5 gallon bucket.

Cut a 2 inch high ring out of a five gallon bucket. Do not use a bucket which stored toxic substances. Grease the inside wall with cooking oil and place the ring on top of a piece of plastic. Mold chicken wire so that it fits against the inner wall of the ring and the floor. Take time to press the wire snug against the edge. One inch of wire should extend above the ring.
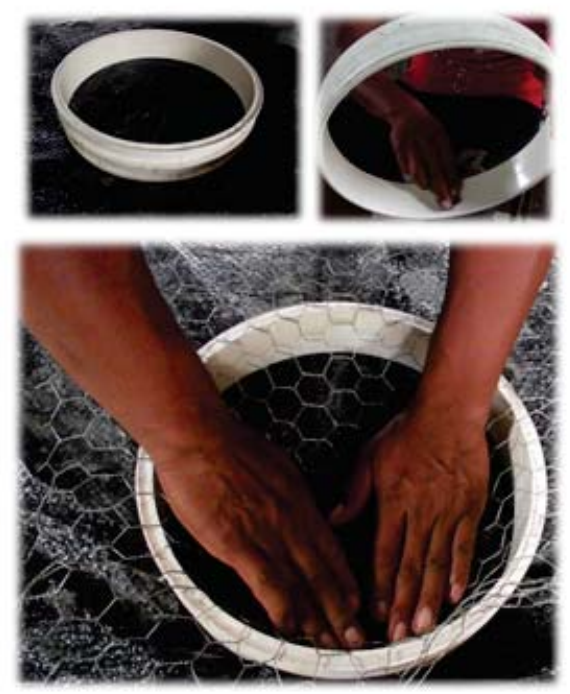

D. Instructions and photo to aid in construction of the base. 
4) Fill mold with cement. Using a 1:1 cement to sand mix, fill the ring mold about 1 inch high. When adding the mix begin by filling the edges and work inward. Create a smooth top with a trowel and let sit for at least two days. During all steps of building this filter it is very important to keep the cement damp and covered while it cures. Once ready remove the cement base from of the plastic ring.

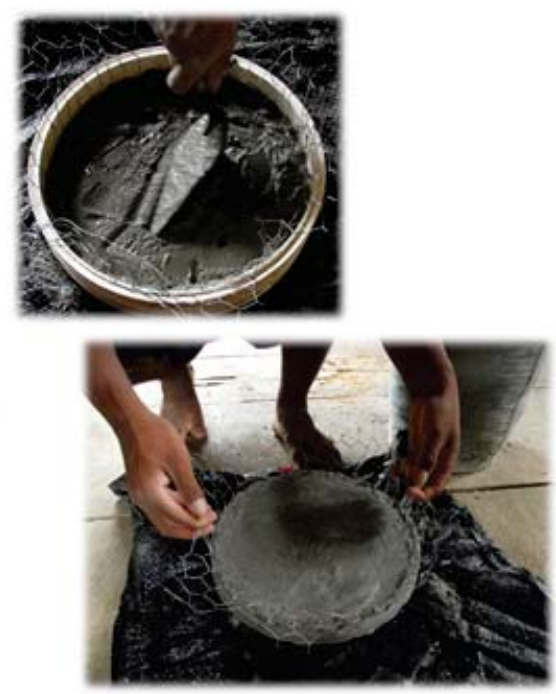

E. Instructions and photo to aid in construction of the base (part 2).

\section{5) Create the} perforated PVC influent pipe.

Cut a 5 inch length of $1 / 2$ " PVC. Use a hack saw to cut slits on upside of pipe and glue a cap and an elbow to either end. Add tape (not shown in picture) to cover the exposed hole of the elbow to prevent cement from entering. Leave the slits uncovered.

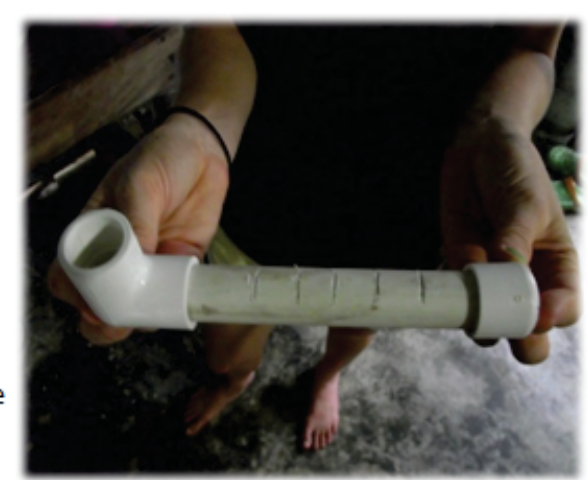

F. Instructions and photo to aid in the construction of the outlet pipe. 


\section{6) Lay pipe and two}

stones on base.

Slide the pipe through a hole of the chicken wire so that the slits and the opening face upwards. Place two stones, about same height as the pipe, on the base so that the mold will stand level.

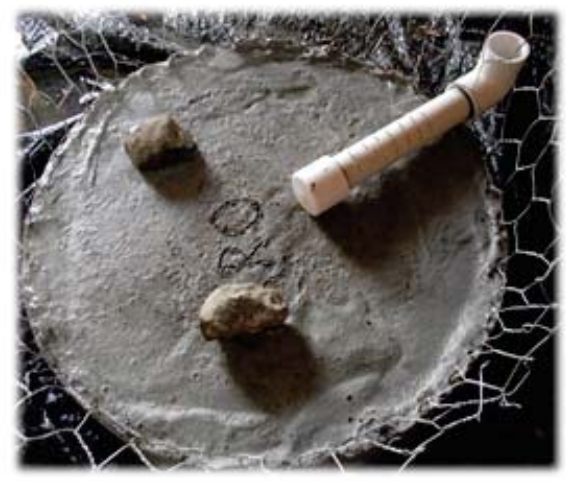

G. Instructions and photo to aid in the setup of the base.

7) Place pipe and filled
bag on top of cement.

The bag should be filled to about 26 inches high. Position the bag over the perforated pipe and base. Use needle nosed pliers to tighten the extra 2 inches of chicken wire to the bag. Place a 5 gallon bucket inside the bag, on top of the dry material. Tie a string tightly around the bag, beneath the bucket so that a shelf will be created once cement is added. It can be helpful to tie the handle of the bucked to the ceiling to keep mold standing straight.

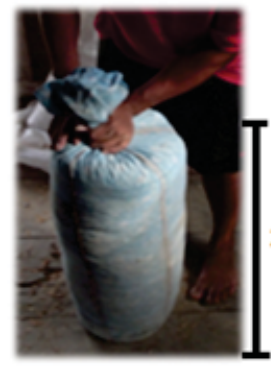

$26^{\prime \prime}$

String

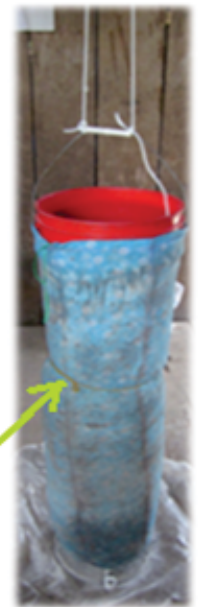

H. Instructions and photo to aid in the setup of the form. 


\section{8) Cement.}

First wet down the outside of the bag (wetter the better). Use a trowel to plaster cement to the chicken wire and the bag adding extra cement around the pipe. The mix ratio should be about 1:2 cement to sand. Allow the

first coat to harden and add another coat. After about 48 hours you should be able to remove the bucket

(Carefully!) and bag by first removing the dry material. Afterwards keep the inside and outside of the filter body covered in plastic and wet for at least three more days.

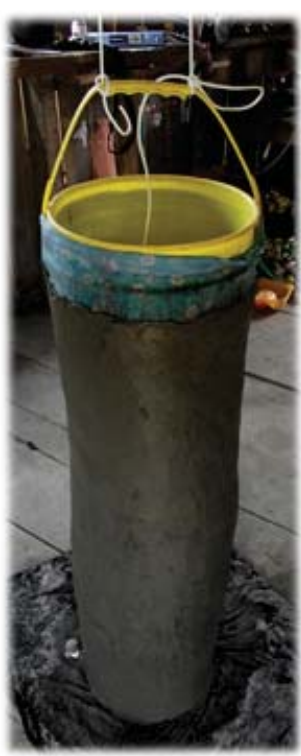

I. Instructions and photo to aid in the plastering of cement

\section{9) Add cement to the} rim and the base.

Add a ring of chicken wire to the outside of the rim and tighten down with pliers. Make a small mix of $1: 1$ cement to sand and coat the chicken wire so that a thick rim is formed. Add water to make the mix wetter and drop cement into the base, sealing the edge where the base meets the wall. Also, drop a blob of cement onto the cap of the pipe for extra support. Do not cover the pipe slits with cement!
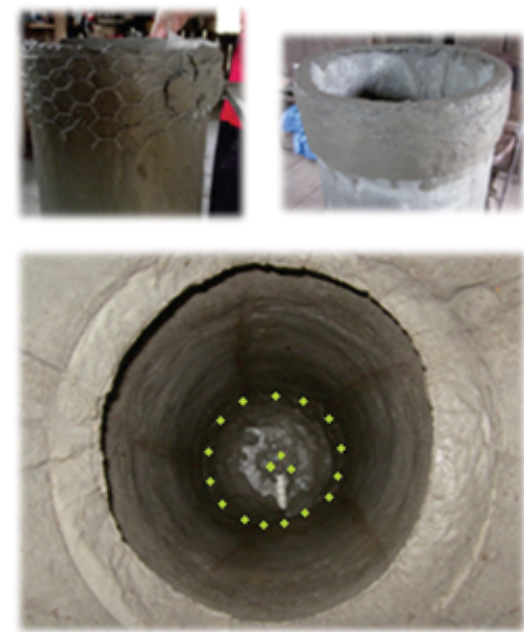

J. Instructions and photo to aid in inner plastering and the construction of the lip. 


\section{0) Wash the sand}

and gravel.

To wash the sand, place it in a bucket and fill the bucket with water. Stir the sand by hand until the water is brown. Dump out the water and repeat.

When the agitated sand no longer makes the water murky the sand is sufficiently clean. Note: the water should not be perfectly clean since this will cause the filtered water to pass through too easily.

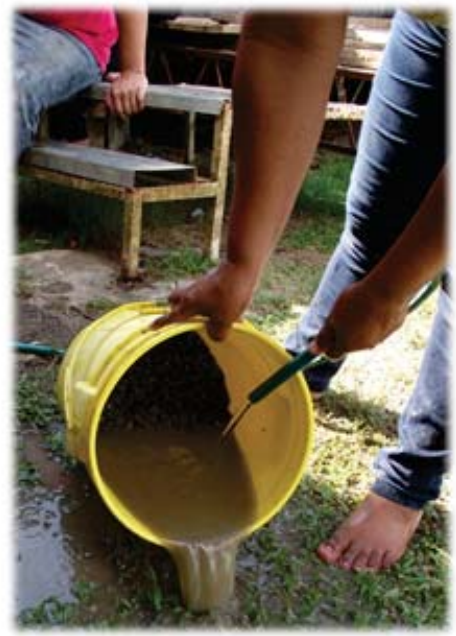

K. Instructions and photo to aid in the washing of sand.

\section{1) Add the pipes and sand.}

The pipe should include two more elbows and should rise about 27 inches above the base. Follow Figure A diagram when cutting and gluing pipes. Move filter to permanent location and then add the washed sand/gravel according to the figure. Flush the filter continually until the water exiting the pipe is clear.

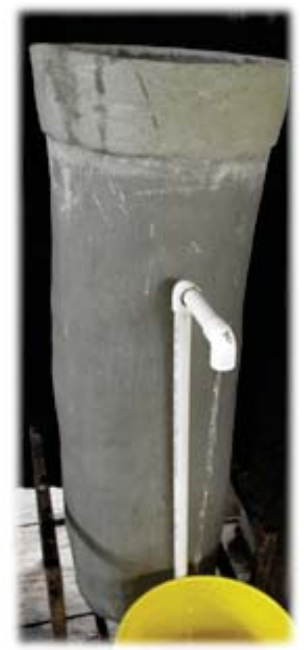

L. Instructions and photo to aid in connection of the outlet pipe. 


\section{2) Build diffusion plate}

Cut the base of a 5 gallon bucket up to 2 or 3 inches. Use a nail or drill to make holes in the base for water to pass through. Place the diffusion plate inside the filter and place several clean stones inside of it. The diffusion plate should sit on the cement shelf created by tying the string around the sack mold in step 7. Its purpose is to prevent poured water from disturbing the top layer of sand.
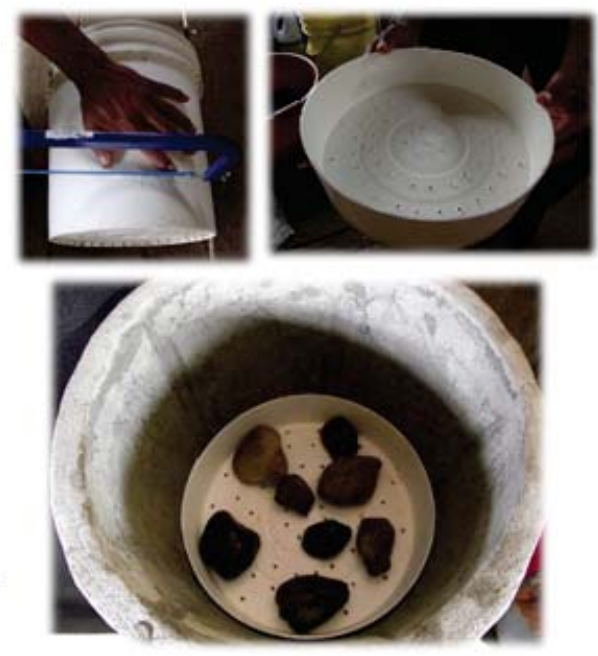

M. Instructions and photo to aid in the construction of the diffusion plate.

\section{Filter best practices:}

- You can begin using the filtered water as soon as it appears clean but water will continue to improve in quality over the next month of use.

- Use two separate water containers to operate this filter. One for adding untreated water from your source and the second as a receptacle for clean water. The second container should be kept clean and never contact unfiltered water.

- Add chlorine to the container of filtered water ( 3 drops/gallon if using $3.5 \%$ sodium hypochlorite to achieve $5 \mathrm{ppm}$ ) and allow it to sit for $1 / 2$ hour before drinking. Never add chlorine to the filter itself.

- Always maintain two inches of water above your top layer of sand.

- Best to use filter at least once every 3 days and no more than once per day.

- Mix Sika with cement to make the filter more water impermeable.

N. Description of the "best practices" to keep in mind during construction.

Figure 23. Instructions for FBSF construction in rural areas (visuals and instructions prepared by author). This is a multipart figure and the descriptions of each step are given under each slide as parts $A$ through $N$. 


\section{Appendix B - Ferrocement Biosand Filter Performance Data}

Table 5. Results from the field testing of 20 ferrocement biosand filters in rural Panama.

\begin{tabular}{|l|rrrr|}
\hline Name & Colonies & Ecoli & \multicolumn{1}{c|}{ Filtered Colonies } & Filtered Ecoli \\
\hline Addiel & 100 & 1 & TMTC & 0 \\
\hline Fidencio & 180 & 0 & 11 & 0 \\
\hline Dorindo & 15 & 0 & 9 & 0 \\
\hline Ricardo & 160 & 0 & 9 & 0 \\
\hline River & TMTC & 11 & 9 & 0 \\
\hline My filter & 140 & 1 & 4 & 0 \\
\hline PC filter & 140 & 1 & 2 & 1 \\
\hline Beto & 100 & 1 & TMTC & 0 \\
\hline Freddy Guerra & 120 & 2 & 60 & 2 \\
\hline Maribel Perez & 320 & 0 & 34 & 0 \\
\hline Orbencio Gonzolez & 160 & 1 & 5 & 0 \\
\hline Challa Rodriguez & 118 & 1 & 65 & 1 \\
\hline Ilka Barria & 200 & 0 & 8 & 4 \\
\hline Diogenes & 300 & 1 & 0 & 0 \\
\hline Marcelina Noriega & 140 & 3 & 1 & 0 \\
\hline Elbia Barria & 200 & 3 & 0 & 0 \\
\hline Juaquine Rodriguez & 240 & 3 & 13 & 0 \\
\hline Bismeisy Guerra & 80 & 2 & 0 & 0 \\
\hline Humberto Mendez & 220 & 3 & 0 & 0 \\
\hline Marcel B Barria & 100 & 3 & 0 & 0 \\
\hline Sandra Pinzon & 120 & 3 & 34 & 0 \\
\hline Mercedes Ojo & 420 & 6 & & \\
\hline
\end{tabular}

